\title{
Molecules released by helminth parasites involved in host colonization
}

\author{
Jolanta M. Dzik ${ }^{凶}$ \\ Nencki Institute of Experimental Biology, Polish Academy of Sciences, Warszawa, Poland; \\ ${ }_{\text {e-mail: j.dzik@nencki.gov.pl }}$
}

Received: 05 September, 2005; revised: 22 November, 2005; accepted: 23 November, 2005 available on-line: 12 January, 2006

\begin{abstract}
Parasites are designed by evolution to invade the host and survive in its organism until they are ready to reproduce. Parasites release a variety of molecules that help them to penetrate the defensive barriers and avoid the immune attack of the host. In this respect, particularly interesting are enzymes and their inhibitors secreted by the parasites. Serine-, aspartic-, cysteine-, and metalloproteinases are involved in tissue invasion and extracellular protein digestion. Helminths secrete inhibitors of these enzymes (serpins, aspins, and cystatins) to inhibit proteinases, both of the host and their own. Proteinases and their inhibitors, as well as helminth homologues of cytokines and molecules containing phosphorylcholine, influence the immune response of the host biasing it towards the anti-inflammatory Th2 type. Nucleotide-metabolizing enzymes and cholinesterase are secreted by worms to reduce inflammation and expel the parasites from the gastrointestinal tract. An intracellular metazoan parasite, Trichinella spiralis, secretes, among others, protein kinases and phosphatases, endonucleases, and DNA-binding proteins, which are all thought to interfere with the host cellular signals for muscle cell differentiation. Secretion of antioxidant enzymes is believed to protect the parasite from reactive oxygen species which arise from the infection-stimulated host phagocytes. Aside from superoxide dismutase, catalase (rarely found in helminths), and glutathione peroxidase (selenium-independent, thus having a poor activity with $\mathrm{H}_{2} \mathrm{O}_{2}$ ), peroxiredoxins are probably the major $\mathrm{H}_{2} \mathrm{O}_{2}$-detoxifying enzymes in helminths. Secretion of antioxidant enzymes is stage-specific and there are examples of regulation of their expression by the concentration of reactive oxygen species surrounding the parasite. The majority of parasite-secreted molecules are commonly found in free-living organisms, thus parasites have only adapted them to use in their way of life.
\end{abstract}

Keywords: helminths, proteinases, proteinase inhibitors, Th2 immune response, kinases, phosphatases, phosphorylcholine, acetylcholinesterase, cytokines, ROS, superoxide dismutase, peroxiredoxins

The success of host colonization by a parasite depends on its abilities to subvert the host immune defense and to survive in the host for extended periods. The most striking features of parasitic helminths are long-term persistence within the host, the ability to elicit protective immunity only after many years of exposure, and complex developmental cycles often involving stage-specific antigens.
Among the numerous parasite species, helminths (nematodes, cestodes and trematodes) (Table 1) appear to follow extremely varied and complicated routes of infection of the host tissues. There are, however, some patterns of similarities in the migratory routes of various parasites, largely dictated by the anatomical make up of the mammalian host. Infections mainly originate in the ingestion

Abbreviations: Ac-API, Ancylostoma caninum aspartyl proteinase inhibitor; AchE, acetylcholinesterase; BMP-1, bone morphogenetic protein-1; CEI, chymotrypsin/elastase inhibitor; ES, excretory/secretory; E-64, cysteine proteinase-specific inhibitor; GH, growth hormone; IEC, intestinal epithelial cell; IGF, insulin-like growth factor; iNOS, inducible nitric oxide synthase; LPS, lipopolysaccharide; MIF, migration-inhibitory factor; $\mathrm{mMCP}$, mouse mast cell proteinase; PGF, plerocercoid-produced growth hormone-like factor; PBMC, peripheral blood mononuclear cells; PC, phosphorylcholine; PRX, peroxiredoxin; SAP, sphingolipid activator protein; Tco-API; Trichostrongylus colubriformis aspartyl proteinase inhibitor; Ts-TCI, Trichuris suis trypsin/chymotrypsin inhibitor; VIP, vasoactive intesinal polypeptide. 
Table 1. Characterization of parasite helminths discussed in the text

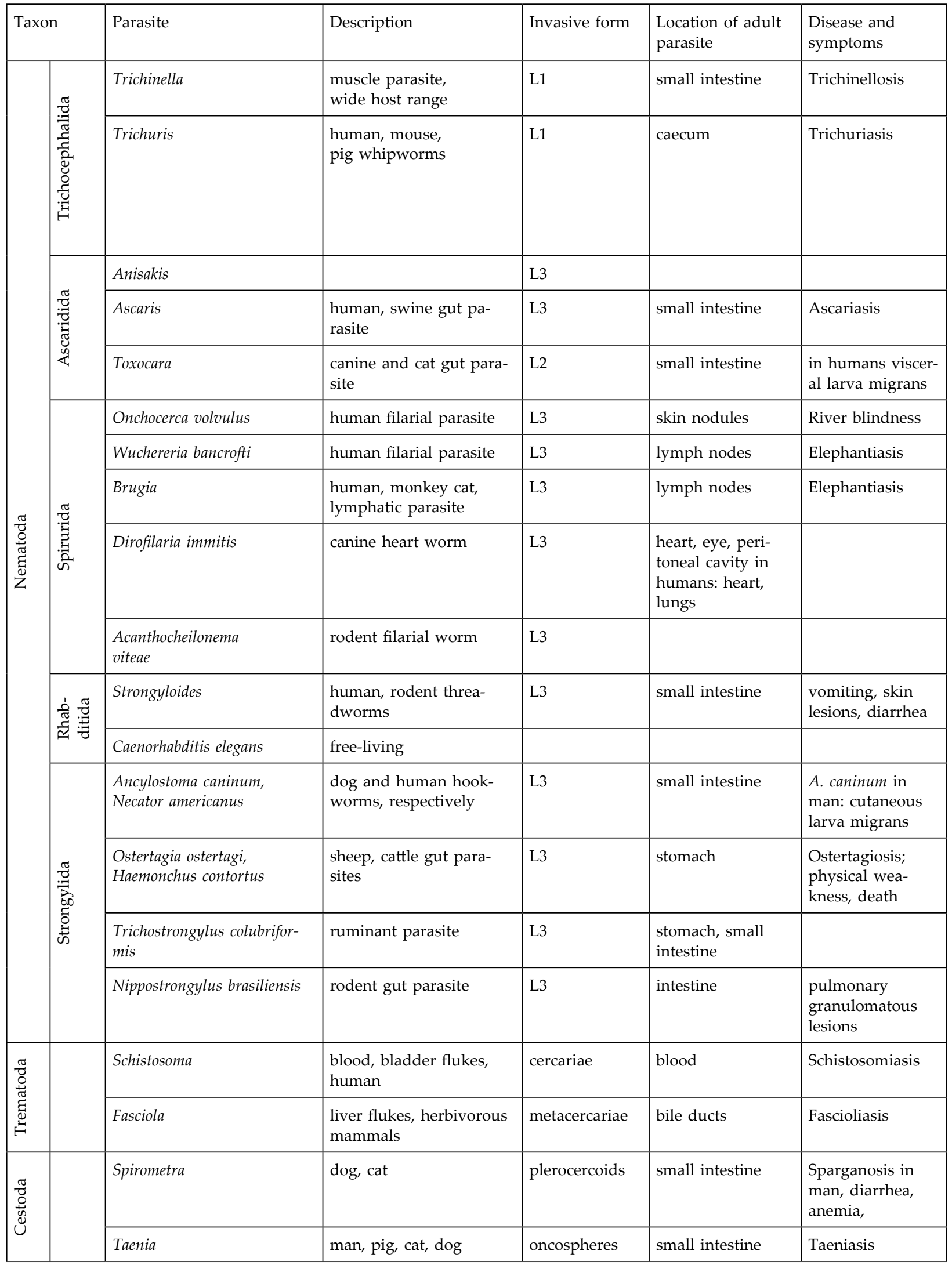

of eggs/larvae (oral route) or in active penetration of the skin by parasite larvae or their vectors (percuta- neous route). After oral infection and a brief occupation of the gastrointestinal tissues by the larval stag- 
es, some parasitic nematodes, roundworms (Haemonchus, Ostertagia, and Trichostrongylus), remain in the gastrointestinal tract for the rest of their life, being localized in the lumen as adults. The infective larvae of some helminth parasites, however, penetrate the intestinal tissue and are transported by the venous blood flow to the liver. Most nematode larvae that follow this route undergo larval moult in the liver. Then, they are transported by venous blood flow to the heart and, via the pulmonary artery, to the lungs. In the lungs, most nematode larvae are temporarily arrested in the capillaries and alveoli. Subsequently, they ascend the respiratory tree to enter the pharynx where they are coughed up and re-swallowed. Their life cycle ends in the intestine where they mature to the adult stage. This migratory route is typical for Ascaris, Ancylostoma hookworm and Toxocara canis in young dogs. Several nematode parasites like $A n$ cylostoma and Toxocara can follow both the oral and percutaneous infection routes to arrive in the lungs of the host.

Filarial nematodes are vectored by arthropods; they mature and mate in specific host tissues. Adult filariae dwell in various human tissues where they can live for several years. The lymphatic filariae Wuchereria bancrofti and Brugia malayi reside in lymphatic vessels and lymph nodes. Developing males and females of Onchocerca volvulus accumulate in subcutaneous tissue where they usually induce formation of nodules. Adult female worms produce microfilariae which circulate in the blood, except for those of Onchocerca volvulus and Mansonella streptocerca, occurring in the skin. The microfilariae infect biting arthropods (mosquitoes for the agents of lymphatic filariasis, blackflies for O. volvulus). Inside the arthropod, the microfilariae develop in one to two weeks into infective filariform (third stage) larvae. During subsequent blood consumption by the insect, the larvae infect the vertebrate host. The larvae migrate to the appropriate site of the host body, where they develop into adults. It is a slow process which can last as long as one year.

The migration profiles of the major trematode parasites (flukes) differ significantly from those of gastrointestinal nematodes. The blood flukes (schistosomes) also follow the percutaneous route to the lungs, but are then carried to and settle in the portal vein (S. mansoni) or in mesenteric veins (S. haematobium and S. japonicum). Pairing of male and female worms takes place before they migrate to the small mesenteric veins and egg laying commences. Eggs lodge in the intestinal capillaries (or in the capillaries of the urinary bladder in the case of schistosomosis japonicum) and pass through the wall of the intestine (or of the urinary bladder) into the lumen of these organs, aided by an inflammatory process surrounding the eggs. A proportion of the eggs laid in the mesenteric veins are swept through the hepatoportal bloodstream to the liver where a similar inflammatory process causes the major pathology associated with the infection. The liver flukes (Fasciola hepatica and $F$. gigantica) do not take advantage of the host's circulatory system for their transport. Newly excysted juvenile flukes actively migrate through the intestinal wall into the peritoneal cavity. Either by chance or through an as yet unknown chemotactic process, the juvenile flukes find the liver and penetrate the liver capsule. After several weeks of active burrowing through the liver tissue, they localize in the bile ducts where they mature and lay eggs that drift with the bile into the intestine. The flukes of medical importance reproduce sexually in definitive vertebrate hosts and asexually in snail intermediate hosts. Flukes have a variety of different life cycle stages. Hatched, free-swimming miracidia infect snails, in which they give rise to sporocysts and rediae. The snails emit cercariae, which infect vertebrate hosts either directly or via an encysted form known as a metacercaria.

The life cycle of cestodes (tapeworms) involves definitive and one or more intermediate hosts. If the intermediate host is a mammal - and this may include man as an accidental host - the hooked larva penetrates the gut wall and is distributed throughout the body via the blood and the lymphatic system. In the sites of predilection of the intermediate host it develops into an infective cyst. The cyst, which already contains a rudimentary scolex (head), may then for example be ingested with the raw flesh of the intermediate host by the final host (dog, cat). In the intestinal tract of the final host the scolex becomes exposed and attaches itself to the intestinal mucosa, where the tapeworm develops into the adult form. Each type of life cycle has specialized larval forms (cysticercus, cysticercoid, coenurus, hydatid cyst, coracidium, procercoid, plerocercoid).

Although the term "helminth parasites" covers polyphyletic groups such as nematodes on one hand, and trematodes and cestodes on the other, all parasitic organisms have a common history of life with the rest of free-living creatures, thus they must use universal molecules in a wide variety of adaptive functions. This review will focus on the enzymes and other molecules secreted by helminths, which are thought to assist in host tissue colonization. Many of these molecules are immunogenic but this issue is beyond the scope of the present review.

This review is addressed to biochemists. Its main aim is to show that experimental biochemistry does not need to be based only on mammalian models. Parasitic invertebrates are also worth the trouble. Many aspects of their physiology are more universal and easier to study than one might expect. 


\section{PROTEINASES}

Proteinases hydrolyze peptide bonds. On the basis of important chemical groups in their active site, proteinases are separated into major classes: serine, aspartic, metallo- and cysteine proteinases. Proteinases catalyze a broad spectrum of important biological reactions leading to activation of enzymes, hormones and peptide trophic molecules. These enzymes are involved in blood coagulation and fibrinolysis, protein metabolism, immune reactions, and tissue remodeling (for review: McKerrow, 1989; Tort et al., 1999).

Secretion of enzymes is a common feature of both free-living and parasitic organisms. Proteinases are required for the emergence both of free-living and parasitic protozoa, helminths and arthropods from protective cysts, eggs or cuticles. In the case of nematodes, which are moulting animals, this process is controlled hormonally (like in insects) and proteolytic enzymes are involved in the digestion of proteins associated with the cuticle and, in some instances, in resorption of the old cuticle proteins. These are leucine aminopeptidases, zinc metalloproteinase and cysteine proteinases (Page in Kennedy \& Harnett, 2001). The ability to secrete proteinases hydrolyzing cuticle collagens is shared by the freeliving nematode Caenorhabditis elegans (Wada et al., 1998) and parasitic nematodes. Proteinase secretion occurs also during cell migration accompanying growth of gonads in C. elegans (Moerman, 1999). Maternal cysteine proteinase is essential for $C$. elegans embryogenesis, as loss of the enzyme activity leads to aberrant processing and/or conformational changes in yolk proteins, resulting in abnormal platelet fusion (Britton \& Murray, 2004). Thus, secretion of proteinases for these purposes is universal among free-living and parasitic organisms.

However, the use of proteinases to degrade the extracellular matrix appears to be unique to parasitic organisms, since larvae and adults of the free-living C. elegans do not secrete proteinases and do not degrade the extracellular matrix (Lackey et al., 1989). Specific release of digestive enzymes after infection of a host serves an integral function in the transition of a free-living larva to parasitism (Hawdon et al., 1995; Gamble \& Mansfield, 1996). In parasites, proteinases facilitate invasion of host tissues and digest host proteins. Additionally, they help parasites to evade the host immune response, prevent blood coagulation (McKerrow, 1989) and have potentiating effects on growth (Phares, 1996) (Table 2).

\section{Extracellular protein digestion}

Metallo- and serine proteinases are known to act in tissue/cell invasion processes in parasitic or- ganisms, but recently cysteine proteinases have been implicated in invasion by many helminths (Sajid \& McKerrow, 2002). Some of these enzymes are secreted by helminths that invade and/or feed on tissues, such as Haemonchus contortus, Nippostrongylus brasiliensis, Strongyloides ratti and Ancylostoma caninum. Cysteine proteinases of parasitic helminths function in a broader chemical environment than the homologous host enzymes. Mammalian lysosomal cysteine proteinases are active at low $\mathrm{pH}$, but relatively unstable at neutral $\mathrm{pH}$ when compared with the parasite orthologues (reviewed in Sajid \& McKerrow, 2002), the exception being mammalian cathepsin S. In marked contrast to the vertebrate proteinases the parasite enzymes are more active and remain stable at neutral $\mathrm{pH}$. This broad $\mathrm{pH}$ profile of the parasite cysteine proteinases is consistent with the numerous extra lysosomal functions that have been characterized. Molecular phylogeny suggests that cysteine proteinases arose early in evolution to degrade proteins both intra- and extracellularly (Sajid \& McKerrow, 2002). There is a wealth of examples of degradation of exogenous proteins in parasitic protozoans, helminths, and arthropods (McKerrow et al., 1993; Tort et al., 1999).

\section{Digestion of hemoglobin}

Two of the best-characterized parasite proteinase systems that catalyze the degradation of host proteins are the hemoglobin degrading activity of a falcipain 2 of the malarial parasite Plasmodium falciparum in its digestive vacuoles (Shenai et al., 2000) and of the fluke Schistosoma mansoni cathepsin-B1 in the worm's gut (Dalton et al., 1995; Fig. 1). It is likely that an analogous hemoglobinolytic proteinase system exists also in another fluke Fasciola hepatica, where activation of a number of cysteine proteinases including cathepsin B-like, cathepsin L-like, dipeptidylpeptidase I and asparaginyl endopeptidase have been identified. A similar pathway for hemoglobin and also fibrinogen degradation may occur in excretory/secretory (ES) products of blood-feeding nematodes.

The adult Necator americanus parasitizes the small intestine of man. The worms hold onto the intestinal wall and feed on blood and tissue exudates. Adult N. americanus ES products contain a heterogeneous mixture of proteolytic activities in vitro; at least two cysteine proteinases, a cathepsin B-like proteinase and a cathepsin L-like one, aspartic- and serine proteinases (Brown et al., 1995), additionally anti-coagulant properties have previously been ascribed to a metalloproteinase in ES from adult hookworms (Hotez \& Cerami, 1983). It is believed that proteolytic enzymes are necessary for adult hookworms for two reasons. They digest host tissue and 
Table 2. Proteinases of helminths known as important for host-parasite relationships

\begin{tabular}{|c|c|c|c|}
\hline \multicolumn{3}{|c|}{ Proteinase families } & Parasites and description \\
\hline \multirow{6}{*}{ 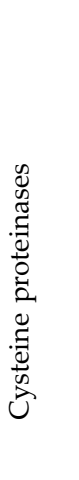 } & \multirow[t]{4}{*}{ Family C1 Papain-like } & Cathepsin B-like & $\begin{array}{l}\text { Schistosoma, Fasciola, Ancylostoma, Necator, Ascaris, Strogyloi- } \\
\text { des, H. contortus, Ostertagia, Trichuris, O. volvulus, C. elegans }\end{array}$ \\
\hline & & Cathepsin L-like & $\begin{array}{l}\text { Paragonimus, Spirometra, Schistosoma, Fasciola, Strongyloides, } H \text {. } \\
\text { contortus, Brugia, Toxocara, Ancylostoma, Ascaris, C. elegans }\end{array}$ \\
\hline & & Cathepsin S & Spirometra mansoni (plerocercoids) \\
\hline & & $\begin{array}{l}\text { Cathepsin } C=\text { Dipeptidyl } \\
\text { peptidase } 1\end{array}$ & Schistosoma japonicum, Haemonchus contortus \\
\hline & \multicolumn{2}{|l|}{ Family C2 Calpain-like } & S. mansoni, S. japonicum, C. elegans \\
\hline & $\begin{array}{l}\text { Family C13 } \\
\text { Legumain-like }\end{array}$ & Asparaginyl endopeptidase & S. mansoni, S. japonicum, F. hepatica, C. elegans \\
\hline \multirow{6}{*}{ 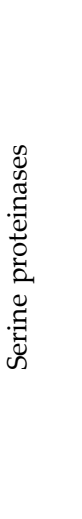 } & \multirow{4}{*}{$\begin{array}{l}\text { Family S1 } \\
\text { Chymotrypsin }\end{array}$} & Elastase & Schistosoma, Onchocerca lienalis \\
\hline & & Chymotrypsin-like & $\begin{array}{l}\text { Schistosoma (cercariae), Schistocephalus solidus (procercoids; } \\
\text { collagenolytic activity), Spirometra mansoni (plerocercoids; } \\
\text { cleaves IFN- } \gamma \text { ) }\end{array}$ \\
\hline & & Trypsin-like & $\begin{array}{l}\text { Anisakis simplex, Spirometra mansoni (plerocercoids; collageno- } \\
\text { lytic activity), Schistosoma (cercariae; elastase activity) }\end{array}$ \\
\hline & & Kallikrein-like & $\begin{array}{l}\text { Trichuris muris, Onchocerca volvulus, Hymenolepis diminuta, } \\
\text { Schistosoma mansoni }\end{array}$ \\
\hline & Family S8 Subtilisin & Blisterase & Onchocerca volvulus \\
\hline & $\begin{array}{l}\text { Family S10 } \\
\text { Carboxypeptidase C }\end{array}$ & Cathepsin A & Nippostrongylus brasiliensis \\
\hline \multirow{3}{*}{ 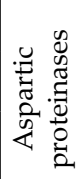 } & \multirow[t]{3}{*}{ Family A1 Pepsin } & Cathepsin D & Schistosoma japonicum \\
\hline & & Cathepsin E & Onchocerca volvulus \\
\hline & & Aspartic endopeptidase & Schistosoma mansoni \\
\hline \multirow{5}{*}{ 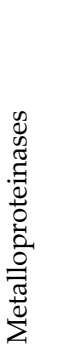 } & Family M12 Astacin & Astacin & $\begin{array}{l}\text { Strongyloides stercoralis, Trichinella spiralis, Ancylostoma cani- } \\
\text { num }\end{array}$ \\
\hline & \multirow{4}{*}{$\begin{array}{l}\text { Other helminth metal- } \\
\text { loproteinases }\end{array}$} & Collagenase & Brugia malayi, Schistosoma mansoni, Gymnorhynchus gigas \\
\hline & & Dipeptidyl peptidase III & Schistosoma mansoni \\
\hline & & Metalloaminopeptidase & Schistosoma mansoni \\
\hline & & $\begin{array}{l}\text { Metalloproteinases with } \\
\text { elastase activity }\end{array}$ & Onchocerca volvulus, Strongyloides stercoralis \\
\hline
\end{tabular}

also impede the potentially damaging host-derived coagulation events (Brown et al., 1995). Haemonchus contortus is a blood-sucking nematode occurring in the fourth stomach of sheep and other ruminants. The L4 larvae and adults of $H$. contortus cause considerable damage to the mucosal lining of the abomasum of infected sheep, resulting in extensive hemorrhages and severe chronic anemia. $H$. contortus would appear to adopt a similar feeding strategy to hookworms. ES proteinases from adult $H$. contortus also degrade fibrinogen and plasminogen and this degradation is, in part, due to cysteine- and aspartic proteinases (Karanu et al., 1993; Knox, 1994). It is interesting that the uptake of radiolabeled hemoglobin by adult parasites in vitro is not inhibited by a cysteine proteinase inhibitor, although hemoglobin breakdown in the culture medium is reduced by $50 \%$ (Fetterer \& Rhoads, 1997b). Thus it is possible that cysteine proteinases are functional in the extra corporeal digestion of the blood meal but are not 
required for the uptake of the products. The latter function may be mediated by metallo- and serine proteinases.

\section{Nematode proteinases in host tissue invasion}

Connective tissue, as well as blood vessel walls, contain abundant quantities of elastin and collagen, thus secreted collagenolytic and elastinolytic enzymes could potentially facilitate the parasite's access to host tissues.

Adult $H$. contortus and L4 larvae degrade the extracellular matrix produced by smooth-muscle cells in vitro (Rhoads \& Fetterer, 1996). Degradation of matrix involves the specific action of cysteine proteinase and is not simply the result of mechanical disruption by motile worms. Significantly, both live adult parasites in culture and adult ES products degrade the glycoprotein elastin and collagen components of the matrix produced in vitro by smooth muscle cells. The secreted cysteine proteinases are thus able to hydrolyze glycoproteins, which function as anchoring proteins essential in maintaining the structural integrity of the matrix. In addition, the ability of cysteine proteinases to degrade both elastin and collagen components of the matrix is similar to that of mammalian cathepsin L. However, the $H$. contortus enzyme is active over a broad range of acidic and alkaline $\mathrm{pH}$ (Karanu et al., 1993; Rhoads \& Fetterer, 1995). Thus, this property might ensure the parasite flexibility to modify or modulate host proteins or affect processes involving tissue destruction, anticoagulation, nutrition, and immune evasion. Cysteine proteinase activity could be important for the penetration of the abomasal mucus layer. It is worth mentioning that proteinases released by Ostertagia ostertagi, a bovine abomasal nematode, have been found to degrade bovine mucin (Geldhof $e t$ al., 2000).

Trichinella spiralis is a nematode with an amazing lack of host specificity. The infective-stage larvae after being released from their capsules in the host's stomach penetrate into the epithelial cells of the small intestine. Therefore, degradation of the extracellular matrix is an essential requirement for tissue invasion and feeding (Appleton in Kennedy \& Harnett, 2001). The L1 larva of T. spiralis has no oral appendages or a stylet. The larvae invade epithelial cells "head first". It has been shown that larvae wound the plasma membranes of rat intestinal epithelial cell line (IEC-6); that is, they create transient breaches in the membrane. Wounding is considered to be a common occurrence in intestinal epithelia. The ES products of the infective stage larvae of T. spiralis contain serine, aspartic and cysteine proteinases (Criado et al., 1992; Moczoń \& Wranicz, 1999; Lun et al., 2003) and zinc-dependent metallo- proteinases, with a substantial contribution of metalloendoproteinases, e.g., collagenase (Lun et al., 2003). The deduced amino-acid sequence of this 58 $\mathrm{kDa}$ metalloproteinase of $T$. spiralis shows significant homology to both the precursor and active forms of the zinc metalloproteinases $\mathrm{TOH}-2$ of C. elegans and various protein members of the astacin family, e.g., tolloid and BMP-1. Astacin metalloproteinases synthesized as zymogens are post-translationally activated (Stöcker et al., 1995). They have diverse functions, e.g., food digestion (Stöcker \& Zwilling, 1995), eggshell hatching (Yasumasu et al., 1992) and hydrolysis of extracellular matrix components such as type I collagen (Yan et al., 2000). During the intestinal phase of worm development, the astacin metalloproteinase should be a key effector molecule for such functions. It is less obvious, however, why adult Trichinella, which reside within the cytoplasm of columnar epithelial cells in the small intestine (Wright, 1979) should require degradation of fibrinogen and plasminogen (Todorova et al., 1995). The authors suggest that secreted proteinases may play an anti-coagulant role, contributing to the pathology of trichinellosis. The elastase activity found in secretions of adult worms may play a role in the degradation of intestinal tissues and, hence, facilitate either the penetration of the parasites into host enterocytes or the release of nutrients (Todorova \& Stoyanow, 2000).

In another species of Trichocephalida, Trichuris muris, secretion of two major peptidases of 85 and $105 \mathrm{kDa}$, respectively, which are serine peptidases (possessing some degree of specificity for collagenlike molecules) was observed to be time-dependent. No peptidase activity was detected in worm extracts, suggesting that these enzymes are activated during or following secretion from worms (Drake et al., 1994). The in vivo functional role of these enzymes remains unclear. They may function in a nutritive capacity. Also, the ability of live worms to degrade basement membrane proteins (Drake et al., 1994) is suggestive of an involvement in the invasive process. These enzymes may aid in the production and subsequent maintenance of the parasite syncytial habitat as the anterior portion of the adult worm becomes embedded within a syncytial tunnel derived from host caecal epithelium (Panesar, 1981). It is possible that action of secreted peptidases disrupts the integrity of epithelial cell membranes leading to cell leakage and thus contributing to the disease pathology (Cooper et al., 1992).

The filaria Onchocerca volvulus is an important nematode parasite of humans affecting the skin and eyes. Two important events in the infection by $\mathrm{On}$ chocerca involve cutaneous tissue migration by larval stages. L3 larvae migrate from the blackfly bite site to subcutaneous locations for adult filariae develop- 
ment, and microfilariae migrate from subcutaneous nodules to distant regions of the skin and sometimes the eye (Lackey et al., 1989). Serine and metalloproteinase activities in ES products of microfilariae and adult males degrade components of the dermal extracellular matrix, collagen type IV, fibronectin and laminin (Haffner et al., 1998). According to the authors, the proteolytic activity in ES products of microfilariae and males is responsible for the degradation of elastic fibers of host tissue as observed in chronic onchocerciasis. Proteinase activity is absent in ES products of females. This could result from different behavior of worms; the infective larvae microfilariae and males must migrate through host tissue while adult females reside in nodules. Stage-specific secretion of Onchocerca $43-\mathrm{kDa}$ serine elastase has been shown in $O$. lienalis, with the enzyme being secreted by L3 larvae but not adult worms. Thus, the serine proteinase of L3 larvae probably plays an important function, facilitating L3 migration from the blackfly bite site to distant regions of the body where adult filariae will develop (Lackey et al., 1989). It is worth mentioning that apart from proteinases, also chitinases could play a role in filarial parasitism.

\section{Filarial chitinases}

Chitinases are enzymes that hydrolyze chitin, a homopolymer of poly- $\beta$ (1-4) linked $N$-acetylglucosamine monomers. Chitin is a part of the exoskeleton of arthropods and is also found in various fungi and bacteria. It has been described as a constituent of the nematode eggshell and eggshell-derived structures (Wharton, 1983). Chitinase activity is associated with nematode eggs, uterine stages and female worms (Adam et al., in Kennedy \& Harnett, 2001). The coincidence between the appearance of chitinase on the sheath of microfilaria (the first larval stage of filarial nematodes) and the ability to infect the arthropod vector is indicative of a role for this protein in liberation of the microfilariae from their sheaths (Fuhrman, 1995). However, infective larvae (L3) of filariae produce and store chitinase inside the intermediate host (Adam et al., 1996), while secretion is triggered by environmental conditions of the vertebrate host and occurs during the early phase of infection and during moulting (Wu et al., 1996). The role of L3 chitinase is not fully understood and different scenarios are possible. Firstly, the protein could contribute to the egress of L3 larvae from the chitinous mouthparts of the vector during the blood meal. Secondly, since the release of chitinase occurs during the first days of culture under vertebrate conditions, the enzyme may act on host molecules during an early stage of infection. It is possible that chitinase interacts with, for example, elements of the extracellular matrix, facilitating the migration through host tissues (Adam et al., in Kennedy \& Harnett, 2001).

\section{Platyhelminth proteinases in invasion}

Unlike the nemathelminthan worms, the platyhelminths (cestodes and trematodes) do not moult. Their body is covered with a syncytial tegument (McLaren \& Hockley, 1977). The tegumental surface is constantly being regenerated and sloughed off into the host bloodstream (Wilson \& Barnes, 1979). The tegument is not only a protective shield for the parasite but performs other important functions at the interface between the parasite and its host (Skelly \& Shoemaker, 1996)

Parasitic trematodes migrate through tissues in one or more stages of their life cycle; however, there are few examples of cysteine proteinases that are involved in tissue migration. The cathepsin Llike proteinases secreted into the gut and regurgitated from $F$. hepatica degraded laminin, collagen and other matrix proteins (Halton, 1997), and a cysteine proteinase located in the cercarial penetration glands of Diplostomum pseudospathaceum is thought to be involved in skin penetration of aquatic birds (Moczoń, 1994). A very interesting study of Fishelson et al. (1992) elucidated how the parasitic blood fluke Schistosoma mansoni synthesizes, stores, and releases a serine proteinase during differentiation of its invasive larvae. In situ hybridization with a cDNA probe allowed to localize the proteinase mRNA in acetabular cells, the first morphologically distinguishable parasite cells that differentiate from embryonic cell masses present in the intermediate host snail. Antiproteinase antibody binding showed that the proteinase progressively accumulated in these cells and was packaged in vesicles of three morphologic types. Extension of cytoplasmic processes containing proteinase vesicles formed "ducts" which reached the anterior end of fully differentiated larvae. During invasion of human skin, groups of intact vesicles were released through acetabular cytoplasmic processes and ruptured within the host tissue. Ruptured proteinase vesicles were noted adjacent to degraded epidermal cells and dermal-epidermal basement membrane, as well as along the surface of the penetrating larvae themselves. These observations are consistent with the proposed dual role for the enzyme in facilitating invasion of host skin by larvae and helping to release the larval surface glycocalyx during metamorphosis to the next stage of the parasite.

Cestodes reside in the gut of their host but the larval stages are involved in tissue invasion. Metalloproteinases are most likely the enzymes facilitating tissue invasion, and has been shown that metalloproteinase present in the migrating larval stage of the cestode Proteocephalus ambloplitis parasit- 


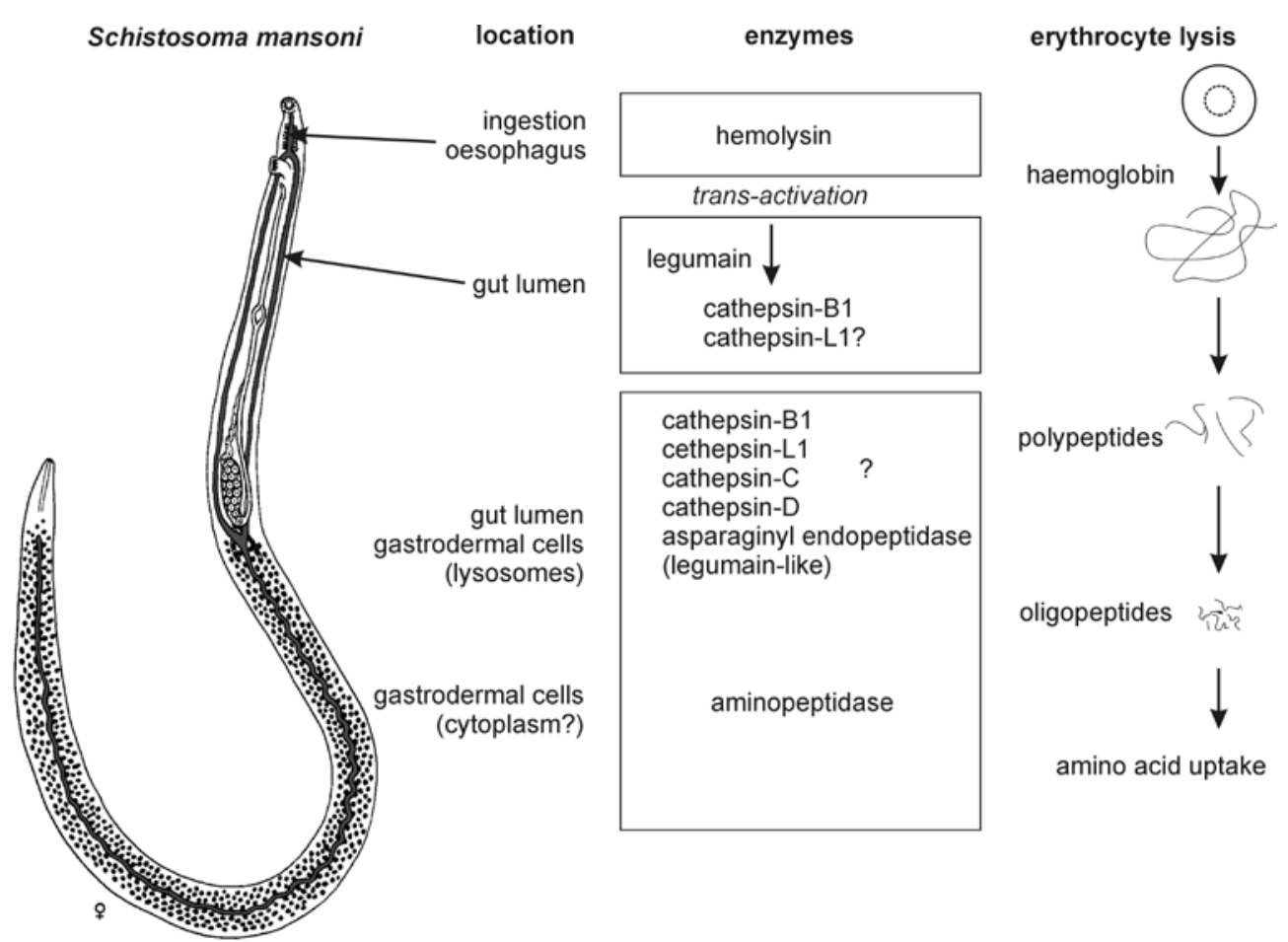

Figure 1. Schematic presentation of hemoglobin digestion by the liver fluke Schistosoma mansoni (based on the Sajid \& McKerrow, 2002).

ic in fishes, has collagenolytic, hemoglobinolytic and slight elastinolytic activity. It is suggested that this proteinase (the only enzyme class present in this larval stage) is secreted from the apical organ during the few-hour migration into host visceral organs (Polzer et al., 1994). In the cestode Schistocephalus solidus parasitizing birds, a chymotrypsin-like proteinase with collagenolytic activity was present in procercoids (but not plerocercoids or adults), possibly being necessary for the penetration of host intestinal wall (Polzer \& Conradt, 1994). Studies in vitro have demonstrated that oncospheres of Hymenolepis diminuta that invade meal beetles by penetrating the wall of their midgut, just after emerging from their embryophores release a serine proteinase from penetration glands (Moczoń, 1996). Plerocercoids (spargana) of another tapeworm Spirometra mansonoides are known to cause sparganosis, a disease caused by granulomatous lesions made around the worm and the tortuous migration track of the sparganum. Sparganosis involves mainly subcutaneous tissues, but may invade visceral organs and the central nervous system. It has been demonstrated that excretory granules from gland cells and myelin-like bodies, synthesized in subtegumental cells of plerocercoids, are released during migration (Osaki, 1990). Within the host tissue, the excreted/secreted proteinases of spargana degrade the extracellular matrix, collagen, fibronectin and myosin, resulting in tissue damage and facilitating migration of the larvae (Song \& Chappell, 1993). It has been documented that excretory/secretory products of Spirometra mansonoides plerocercoids contain tissue-lysing enzymes: cysteine proteinases of $21 \mathrm{kDa}$ and $28 \mathrm{kDa}$, trypticases of 104 and $198 \mathrm{kDa}$, as well as chymase activity corresponding to $36 \mathrm{kDa}$ (Cho et al., 1992; Song \& Chappell, 1993).

Although loss of weight by the host is commonly associated with parasitism, especially among mammals, Mueller (1963) has found that when spargana of S. mansonoides are injected subcutaneously into young female mice, the infected mice show accelerated gain in weight when compared to uninfected mice. This intriguing observation, which cannot be accounted for by the weight of the parasites, has initiated 33-year lasting studies of the unusual hostspirometrid tapeworm relationship. They culminated in the discovery by Phares (1996) that plerocercoids of $S$. mansonoides secreted plerocercoid-produced growth hormone-like factor (PGF).

\section{Growth hormone-like factor of Spirometra}

The growth hormone-like factor of Spirometra plerocercoids (PGF) stimulates growth by increasing the level of IGF-1 (somatomedin/insulin-like growth factor-1). PGF binds to hormone receptor(s) to stimulate growth and lipogenesis. Surprisingly, the biological actions of PGF appear to be more similar to those of human growth hormone than of other vertebrate growth hormones. PGF evokes a dramatic lactogenic response, whereas non-primate growth hormones do not have an ability to bind prolactin receptors and stimulate the lactogenic activity. Ple- 
rocercoids of another species, Spirometra erinacei, also produce and release a growth hormone-like factor (PGF-e). There are distinct differences in its biological characteristics when compared to PGF from $S$. mansonoides. PGF and PGF-e both express growth hormone-like activities by binding growth hormone receptors, increasing IGF-1 activity and stimulating growth. However, PGF expresses only the insulinlike activities of GH, whereas PGF-e shows only anti-insulin/diabetogenic activities, presumably due to differential activation of receptors. Purification of PGF to homogeneity (Phares \& Kubik, 1996) showed the product to be a single protein of $27.5 \mathrm{kDa}$ with human growth factor-like activity. Comparison of the sequence of the plerocercoid protein revealed no homology to human growth factor or to any other hormone. However, the predicted sequence of the 215 amino acids contained in the $27.5 \mathrm{kDa}$ protein does share $40-50 \%$ homology with cysteine proteinases. A fascinating conclusion that the $27.5 \mathrm{kDa}$ plerocercoid protein is both a cysteine proteinase and a growth hormone-like factor is supported by data of Wang et al. (1995) who showed that S. erinacei also expresses PGF-e, a $27 \mathrm{kDa}$ protein with both growth hormone-like and proteinase characteristics.

Addition of a cysteine proteinase-specific inhibitor (E-64) in a concentration sufficient to inhibit all hydrolytic activity, blocks receptor binding of PGF by up to $80 \%$. Also the ability of PGF-e to stimulate proliferation of hepatocytes was inhibited by proteinase inhibitors (Tsuboi et al., 1992). Whereas the $27.5 \mathrm{kDa}$ protein is clearly the most abundant protein in plerocercoids (Phares \& Kubik, 1996), its distribution is restricted to the plerocercoid stage, as no growth-promoting activity of this protein is detected in adult tapeworms or procercoids. The mechanism by which PGF activate the growth hormone receptor is not known.

Wang et al. (1995) demonstrated that PGF-e is present extensively on the external surface of the tegument and in subtegumental cells of plerocercoids of S. erinacei. This finding is in line with various reports of continuous release of PGF into the environment of plerocercoids (cf. Phares, 1996). Of the general protein substrates tested, collagen was the most efficiently hydrolysed one by PGF/proteinase. Therefore, based on its distribution on the surface of the worm and preference for collagen as a substrate, it is reasonable to conclude that an important function of PGF/proteinase is to facilitate tissue penetration by plerocercoids. The proteinase also appears to be involved in sloughing of the plerocercoid body, which occurs after the worms are ingested, but before penetration of the scolex out of the gut into the body cavity of mice (Wang et al., 1995). The availability of an effective collagenase would seem especially important to plerocercoids of Spirometra as they have no hooks or other structural features to enhance tissue penetration. Furthermore, PGF/ proteinase may play an important role for plerocercoids in evasion of the host immune defense system by cleaving IgG, which attaches to the parasite surface (both PGF and PGF-e cleave IgG). A potential role of the GH-like function of PGF/proteinase in completing Spirometra mansonoides complex life cycle is proposed by Phares (1996): PGF stimulates growth, suppresses endogenous growth hormone levels, but does not duplicate the stimulatory effect of growth hormone on immune function (Sharp et al., 1982). Even after obtaining considerable evidence that the $27.5 \mathrm{kDa}$ plerocercoid protein functioned both as a growth hormone-like factor and a cysteine proteinase, no molecules with structural similarity to human growth hormone have been found. PGF is a neutral cysteine proteinase that also binds and activates growth hormone receptors from a variety of species. The serendipitous observation by Mueller in 1963 that plerocercoid-infected mice grow significantly larger than their uninfected littermates has led to the discovery of an equally unique biochemical phenomenon of a cysteine proteinase which is a partial growth hormone agonist.

\section{Helminth plasminogen receptors: enolase}

Plasminogen is a $92 \mathrm{kDa}$ plasma proenzyme of the serine proteinase plasmin, which plays important roles in processes like fibrinolysis and degradation of extracellular matrices (Plow et al., 1995). One of the best-characterized cellular plasminogen receptors in mammals is the glycolytic enzyme enolase (Redlitz et al., 1995). Eukaryotic enolases have been shown to be multifunctional proteins presenting a variety of activities besides the glycolytic one (Pancholi, 2001). Enolase has also been localized on the surface of several pathogens like bacteria, fungi or protozoa (Pancholi, 2001) and very recently in helminths like Onchocerca volvulus (Jolodar et al., 2003) and Fasciola hepatica (Bernal et al., 2004). Enolase from $F$. hepatica excretory-secretory products binds human plasminogen in vitro and this suggests that enolase may function as a plasminogen receptor. These studies suggest an important role of this association for the invasion of host tissues by the pathogenic agent (Pancholi, 2001) as recent reports have pointed to an enhanced activation of plasmin(ogen) upon interaction with the pathogen-derived enolase (Lähteenmäki et al., 2001; Jong et al., 2003). The plasminogen-binding property of $O$. volvulus and $F$. hepatica enolase may support plasmin-mediated proteolysis, including degradation of the hosts' extracellular matrix, thereby promoting the migration of larval stages through tissues. The recognition of enolase by antibodies in sera of O. volvulus-infected 
persons indicates an involvement of this protein in the interaction between the parasite and the human host.

\section{IMMUNOEVASION}

Investigations of different parasitic infections have provided general statement that resistance to intracellular parasite infections is associated with production of pro-inflammatory cytokines (interferon $\gamma$, IL-2, tumor necrosis factor $\beta$ ) by the lymphocyte subset of $\mathrm{CD}^{+} \mathrm{T}$ helper cells known as Th1 cells evoking Th1-type of immunological response (Fig. 2). Susceptibility to infection has been associated with the Th2 type response originating from a subset of Th2 cells (Street \& Mosmann, 1991). Most helminth infections of humans and animals induce immune responses which are characterized by the production of Th2-associated cytokines IL-4, IL-5, IL-9, IL-10, IL-13, and of antibodies (IgG1 in mouse, IgG4 in man, IgE in both species) by B lymphocytes. This type-2-biased immune phenotype generally persists for the duration of the infection. Among the numerous reported activities helminth-induced type2-associated immune responses have been linked to the expulsion of gastrointestinal nematodes and the formation of circumoval granulomas in the course of schistosomosis (Hoffmann et al., 2002). The regulation of Th1 and Th2 responses has been well studied (Artis \& Grencis in Kennedy \& Harnett, 2001) but a detailed account of Th1/Th2 responses in parasitic infections is beyond the scope of this review. It should be mentioned, though, that these responses are influenced by the type of antigen-presenting cells involved, the presence of co-stimulatory molecules and the cytokine environment present during T-cell receptor engagement. Whereas a number of studies have suggested a role for excretory/secretory products in modulation of host immune responses, both of lymphocytes and macrophages, only very few parasite molecule(s) involved have been identified.

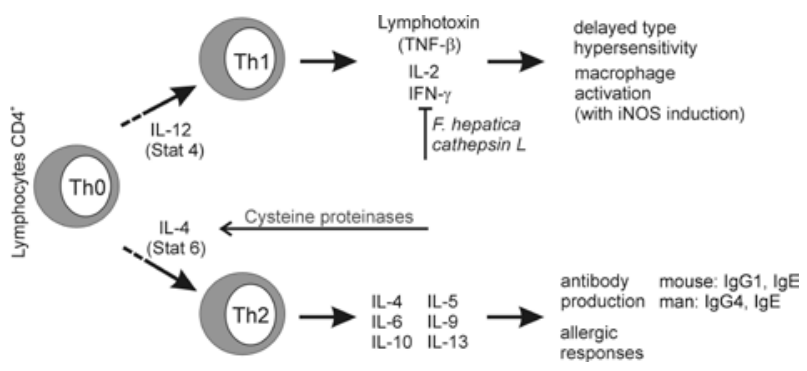

Figure 2. Polarization of Th1/Th2 immune responses under influence of parasitic infection.

Induction of IL-4 and inhibition of IFN- $\gamma$ by helminth cysteine proteinase is marked with gray.

\section{Induction of Th2 response}

Several studies have proposed a role for cysteine proteinases in inhibiting Th1 immunity through the induction of IL-4. Interleukin-4 that is secreted by $\mathrm{CD}^{+} \mathrm{T}$ cells (Fig. 2), as well as by some minor subpopulations of $\mathrm{T}$ lymphocytes and cells of the mast cell lines, is the main cytokine responsible for Th2 differentiation. Machado et al. (1996) who suggested that cysteine proteinases secreted by various pathogens down-regulate Th1 responses by a mechanism involving IL-4, demonstrated that these proteinases induce mast cells and basophils to degranulate and secrete IL-4. In accord, it has been shown that in mice, cathepsin L (a cysteine proteinase) of F. hepatica suppresses production of IFN- $\gamma$, a cytokine of Th1-type response (induced by Bordetella pertusis) (Fig. 2). Moreover, molecules secreted by F. hepatica induce production of IL-4 and IL-10, cytokines of Th2-type response (O'Neill et al., 2001). Other studies with the nematode Brugia pahangi (Osborne \& Devaney, 1999) and the trematode Schistosoma haematobium in urinary schistosomiasis (King et al., 1996) revealed that parasite-reactive Th1 cells were suppressed by a mechanism that involved an up-regulation of IL-10 production which, in turn, coincided with cellular hyporeactivity.

\section{Modulation of $\mathrm{CD}^{+}$expression}

A surface molecule, $\mathrm{CD}^{+}$of $\mathrm{T}$ helper lymphocytes plays an essential role in interactions of lymphocytes with antigen-presenting cells in the generation of $\mathrm{T}$ helper responses. By decreasing $\mathrm{CD} 4^{+}$expression, a parasite may interfere with the generation of the host immune response and hence increase their survival. Fasciola hepatica cathepsin L suppresses sheep $\mathrm{T}$ cell proliferation and reduces surface $\mathrm{CD}^{+}$expression on both human and ovine $\mathrm{T}$ cells (Prowse et al., 2002). A cysteine proteinase found in ES products of Taenia solium metacestodes can decrease $\mathrm{CD}^{+}$expression on human lymphocytes. These data suggest that metacestodes may modulate $\mathrm{CD}^{+}$expression as a way of controlling the host inflammatory response (Molinari et al., 2000). Of note, two metalloproteinases from the Leishmania protozoan have been shown to exhibit similar effects (Hey et al., 1994). Considering the earlier known T. solium metacestode factor, shown to inhibit IL-2, IFN- $\gamma$, IL-4 and TNF- $\alpha$ synthesis as well as lymphocyte proliferation (Arechavaleta et al., 1998), the cysteine proteinase secreted into the host tissue may modulate both the humoral and the cellular host responses. In accord, in histological sections of both human and porcine cysticercosis viable metacestodes are surrounded by a lim- 
ited inflammatory reaction (reviewed in Molinari et al., 2000).

\section{Innate immunity and helminths}

Macrophages are effector cells of innate immunity and their activation brings about among others, production of IL- $1 \beta$, TNF- $\alpha$ and free radicals: superoxide anion, produced by NADPH oxidase and nitric oxide produced by inducible nitric oxide synthase (iNOS). These free radicals have bactericidal and antiparasitic activity, well documented in the case of intracellular parasites. Spirometra erinaceieuropaei infects domestic and wild cats and dogs (Mueller, 1974). In human, an accidental host, the plerocercoids cause sparganosis. Studies of the influence of plerocercoid ES products on macrophages revealed suppression of macrophage pro-inflammatory response induced by a combination of lipopolysaccharide (antigen from the cell wall of Gram $^{-}$bacteria) and IFN- $\gamma$. Plerocercoid ES products suppressed proinflammatory response of macrophages reducing iNOS mRNA expression and production of nitric oxide (Fukumoto et al., 1997). ES products suppressed IL- $1 \beta$ mRNA expression, as well as TNF- $\alpha$ gene expression and TNF production (Dirgahayu et al., 2002; 2004), and IL-6 mRNA level (Tanihata, 1996). Further studies demonstrated that these ES products (possibly a protein of molecular mass $>97 \mathrm{kDa}$ ) interfered with signaling pathways inhibiting ERK1/2 and p38 MAPK phosphorylation induced by lipopolysaccharide (Dirgahayu et al., 2002). The suppression of pro-inflammatory cytokine expression such as IL-1 $\beta$ and TNF- $\alpha$ may be among the mechanisms by which plerocercoids can successfully survive within the host (Fukumoto et al., 1997).

In mice showing Th1 or Th2 response, two different types of macrophage activation have been described, M-1 (classical) involving induction of iNOS and nitric oxide production and M-2 (alternative) involving arginase induction (Mosser, 2003). We have shown that $T$. spiralis infection of guinea pigs does not induce nitric oxide production in lung macrophages (Dzik et al., 2002a; 2002b) exposed to larval antigens when newborn larvae pass to the muscles. Instead, arginase activity is enhanced in these cells (Dzik et al., 2004), concomitantly with respiratory burst induction (Dzik et al., 2006), both being elements of the non-classical type of response. Recently, it has been shown that thioredoxin peroxidase secreted by $F$. hepatica induces the alternative activation of macrophages characterized by the production of high levels of IL-10, a Th2-type cytokine (Donnelly et al., 2005). In view of the foregoing, helminth-induced anti-inflammatory response concerns macrophages as well.

\section{Do helminths produce cytokines?}

The intestinal nematode Trichuris muris has been shown to secrete a protein with homology to IFN- $\gamma$, which binds IFN- $\gamma$ receptors on host lymphocytes and mediates cellular changes similar to those induced by IFN- $\gamma$ itself (Grencis \& Entwistle, 1997). Similarly, one of the ES products (p66) of the tapeworm Taenia crassiceps larvae possesses activities that mimic some characteristics of murine IFN$\gamma$, such as the ability to induce spleen T-cell proliferative responses, and upregulation both of IFN- $\gamma$ and IL-10 production in these cells. Moreover, p66 was able to upregulate nitric oxide production in macrophage cell line (Spolski et al., 2002). The significance both of p66 and the Trichuris muris IFN- $\gamma$ homologue in immunoregulation remains to be elucidated.

Also, two TGF- $\beta$ homologues have been identified in Brugia malayi and one of them, secreted by adult parasites in vitro, is able to bind to host TGF$\beta$ receptors. In the context of a helminth infection, the most intriguing role for a parasite TGF- $\beta$ would be down-regulation of host inflammatory response, such as ablation of nitric oxide generation (Maizels et al., 2001). It is interesting to mention that the cestode Mesocestoides corti releases proteins with homology to stress proteins, which have an ability to alter the isotype profile of the host antibody response (Estes \& Teale, 1991).

A mammalian cytokine, macrophage migration-inhibitory factor (MIF), is involved in the initiation of adaptive immune response and is an essential regulator of T-cell activation (Bacher et al., 1996). The MIF monomer has a secondary structure similar to that of the dimer of IL-8 (Kato et al., 1996). MIF is genetically (Esumi et al., 1998) and structurally (Sugimoto et al., 1999) related to D-dopachrome tautomerase and shares with it the spurious enzyme activity. The physiological substrates of MIF are phenylpyruvate and $p$-hydroxyphenylpyruvate.

A helminth homologue of mammalian MIF was first isolated from Trichinella spiralis (Pennock et al., 1998). MIF homologues have also been found in several filarial nematodes Brugia pahangi, B. malayi, Wuchereria bancrofti and Onchocerca volvulus, and the intestinal nematodes Trichuris muris (Pennock et al., 1998; Pastrana et al., 1998) and T. trichiura (Tan et al., 2001). Immunocross-reactive material was also detected in Ascaris lumbricoides (Pastrana et al., 1998). Mammalian and filarial MIFs have conserved cysteinyl residues, which have been implicated in redox reactions (Kleemann et al., 1998). A comparison of the primary structures of MIFs from $T$. spiralis and $T$. trichiura with those of mammals and other nematodes shows that $T$. spiralis and T. trichiura MIFs share between $25 \%$ and $46 \%$ amino-acid sequence 
identity with other MIFs, including all of the uniformly conserved residues, but are notably lacking in cysteine residues (Tan et al., 2001). Both T. spiralis MIF and human MIF show extremely potent inhibition of monocyte migration and chemotactic activity in serum-free medium (Tan et al., 2001). The amount of MIF secreted by T. spiralis larvae and related to total secreted protein in ES products is much higher (18-55 ng/mg of protein) than the MIF level in normal human plasma $(0.04-0.4 \mathrm{ng} / \mathrm{mg}$ of plasma protein) (reviewed in Tan et al., 2001) and might therefore be sufficient to affect monocyte migration locally

Table 3. Naturally occuring proteinase inhibitors of helminths

\begin{tabular}{|c|c|c|}
\hline \multicolumn{2}{|l|}{ Inhibitor } & Enzyme inhibited \\
\hline \multirow{2}{*}{$\begin{array}{l}\text { Cysteine prote- } \\
\text { inase inhibitors } \\
\text { (cystatins) }\end{array}$} & Brugia malayi Bm CPI-1 & \\
\hline & Brugia malayi Bm CPI-2 & Cathepsin S, B, L, asparaginyl endopeptidase \\
\hline & Acanthocheilonema viteae Av 17 & \\
\hline & Onchocerca volvulus onchocystatin & Cathepsin L, S, cysteine proteinase in moulting \\
\hline & Haemonchus contortus cystatin & \\
\hline \multirow{4}{*}{$\begin{array}{l}\text { Aspartic prote- } \\
\text { inase inhibitors } \\
\text { (aspins) }\end{array}$} & Onchocerca volvulus Ov 33 & Pepsin, cathepsin E \\
\hline & Ascaris suum PI-3 & Pepsin, cathepsin E \\
\hline & Ancylostoma canium Ac-API & \\
\hline & Trichostrongylus colubriformis aspin & \\
\hline \multirow{22}{*}{ 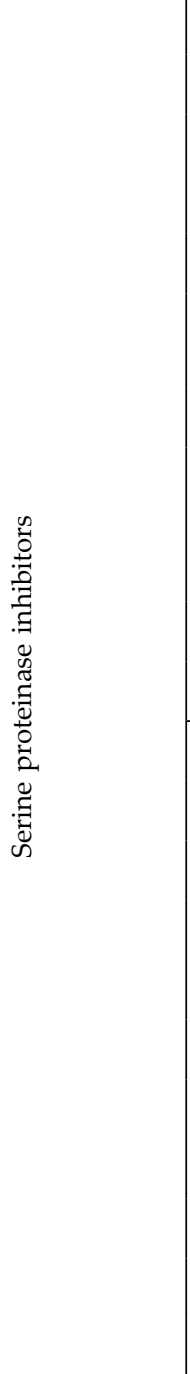 } & Ascaris suum As-SPN & \\
\hline & Brugia malayi Bm-SPN-1, Bm-SPN-3 & \\
\hline & Brugia malayi Bm-SPN-2 & Cathepsin G, neutrophil elastase \\
\hline & Onchocerca volvulus Ov-SPN-1, Ov-SPN-2 & \\
\hline & Onchocerca ochengi Oo-SPN & \\
\hline & Trichostrongylus vitrinus Tv-SPN & $\begin{array}{l}\text { Mast cell proteinase among others host cell protein- } \\
\text { ases }\end{array}$ \\
\hline & Trichinella spiralis serpin & Trypsin \\
\hline & Caenorhabditis elegans SRP-2 & $\begin{array}{l}\text { Granzyme B, lysosomal cysteine proteinases (cathep- } \\
\text { sin } K, \text { L, S, V) }\end{array}$ \\
\hline & C. elegans Ce-SPN-1-SPN-10, & \\
\hline & Schistosoma mansoni Smpi56 & Elastase \\
\hline & Schistosoma haematobium SHSP1 & \\
\hline & Anisakis simplex ASPI-1, ASPI-2 & Elastase \\
\hline & Anisakis simplex ASPI-3 & \\
\hline & Ascaris suum ICE-1, ICE-2-5 & Chymotrypsin, elastase \\
\hline & Ascaris suum ITR-1, ITR-2 & Trypsin \\
\hline & Ancylostoma caninum AcAP5 & Factor Xa, XIa \\
\hline & Ancylostoma caninum AcAP6 & Factor Xa \\
\hline & Ancylostoma caninum AcAPc2 & FactorVIIa/TF \\
\hline & Ancylostoma caninum KI & Trypsin chymotrypsin, pancreatic elastase \\
\hline & Onchocerca volvulus Ov-SPI-1, Ov-SPI-2 & \\
\hline & Trichuris suis Ts-TCI & Trypsin, chymotrypsin \\
\hline & Trichuris suis Ts-CEI & Chymotrypsin, elastase, chymase, cathepsin G \\
\hline
\end{tabular}


in infected tissue. Taken together, the elegant studies on the structural, catalytic and cell-migration-inhibitory properties of $T$. spiralis MIF indicate that it is partially orthologous to mammalian MIF. The occurrence of MIF orthologues in parasitic helminths might contribute to subversion of host defences.

\section{Digestion of immunoglobulins}

One of the important enzymatic activities of helminth proteinases is digestion of immunoglobulins. Cleavage of immunoglobulins by helminth parasite proteinases is important, not only because of the potential for immune evasion of antibodydependent cell cytotoxicity (Carmona et al., 1993) but also due to the fact that degradation of immunoglobulin $\mathrm{G}(\mathrm{IgG})$ produces biologically active material that binds to receptors on immune effector cells and induces cytokine release (Kinet, 1989). Thus, in vivo immunoglobulin cleavage may affect the outcome of some helminth infections. For example, a trypsin-like proteinase or aminopeptidase of Schistosoma mansoni schistosomula can cleave off the Fab fragment when the Fc receptor of the worm binds IgG (Auriault et al., 1981). Immature Fasciola hepatica also release cathepsin B- or L-like proteinases, which cleave mammalian IgG in vitro (Chapman \& Mitchell, 1982; Carmona et al., 1993), and $F$. hepatica cathepsin L has been shown to prevent antibody-mediated attachment of eosinophils to juvenile flukes in vitro (Carmona et al., 1993). The cathepsin S-like proteinase secreted by Spirometra mansoni plerocercoid cleaves IgG (Kong et al., 1994). Metallo-, aspartic-, and cysteine proteinase activities were found in extracts from Taenia solium metacestodes and IgG digestion detected in vitro by these extracts was reported (White et al., 1992). Also, a serine proteinase of Dirofilaria immitis microfilariae was reported to cleave IgG (Tamashiro et al., 1987).

\section{PROTEINASE INHIBITORS OF HELMINTHS}

Proteinases exist in all living organisms and they are involved in various physiological and pathological processes, therefore their activity, if uncontrolled, can be destructive to the cell or organism and must be precisely regulated by endogenous inhibitors. This paragraph is devoted to the inhibitors of cysteine-, serine-, and aspartic proteinases of helminthic origin (Table 3).

\section{Cysteine proteinase inhibitors: cystatins}

Cystatins are reversible, tight-binding inhibitors of cysteine proteinases (Nicklin \& Barrett,
1984) that share some fundamental features, the most prominent being thermostability (Abrahamson, 1994). Cystatins are divided in three major families: the stefins with no disulfide bridges and displaying a mean molecular mass of $11 \mathrm{kDa}$, the cystatins with two disulfide bridges and molecular mass of approx. $14 \mathrm{kDa}$, and kininogens, which are glycoproteins with a relatively high molecular mass ranging from 60 to $120 \mathrm{kDa}$ (Abrahamson, 1994).

The overall consensus regarding the functional aspects of the cystatins is that they act similarly to zymogens, regulating proteinases mainly as inhibitors within the cytoplasm, prior to the release of the active form of the enzymes (Morales et al., 2004). Cystatins are found in mammals but cystatin-like molecules are also present in mammals and parasites (Vray et al., 2002).

Modulation by cystatins of antigen processing and presentation

The first described cystatin of parasite origin was the "onchocystatin" of the human filarial nematode Onchocerca volvulus (Lustigman et al., 1992). This protein was initially thought to regulate parasite proteinases during the moulting of the nematode. However, additional functions outside the moulting process are underlined by the fact that cystatin of the rodent filaria Acanthocheilonema vitae is secreted by male worms and blood-stage microfilariae that do not moult (Hartmann et al., 1997). Investigation of the features of cystatins from both filarial (Schonemeyer et al., 2001) and gastrointestinal nematodes (Dainichi et al., 2001; Newlands et al., 2001) showed them to inhibit the cysteine proteinases cathepsin $\mathrm{L}$ and $\mathrm{S}$ that are involved in the proteolytic processing of polypeptides. Moreover, filarial cystatins possess an additional motif that is required to inhibit a distinct class of cysteine proteinases, the legumains (asparaginyl endopeptidases) and it was shown that B. malayi cystatin has the capacity to inhibit legumain-like proteinases (Manoury et al., 2001). These inhibition profiles imply that the studied nematode cystatins might have a dual function, inhibiting nematode cysteine proteinases as well as host proteinases.

The legumain-like proteinases are involved in the degradation of proteins within the endosomallysosomal compartment of antigen-presenting cells, as well as in the cleavage of the MHC class II-associated invariant chain by aspartic and cysteine proteinases, such as cathepsin S, cathepsin L (Nakagawa \& Rudensky, 1999) and cathepsin F (Shi et al., 2000). In this respect, $N$. brasiliensis cystatin inhibits in vitro processing of ovalbumin by cathepsin B and cathepsin L, suggesting that the same effect occurs in the lysosome during antigen degradation (Dainichi et al., 2001). 
Modulation of cytokine production and $\mathrm{T}$ cell proliferation

Apart of their capacity to inhibit proteinases, nematode cystatins seem to have a profound effect on cytokine production (Fig. 3). Filarial cystatins have been shown to induce the production of several cytokines causing anti-inflammatory responses (Hartmann et al., 1997; Schonemeyer 2001). In this regard, prominent differences were found by an analysis of the cytokine profile of the peripheral blood mononuclear cells (PBMC) exposed to filarial (O.volvulus) or C. elegans cystatins. O. volvulus cystatin induced the release of TNF- $\alpha$ (an event that usually leads to proinflammatory responses), followed by a downregulation of IL-12 production and massive increase of IL-10 production by these cells, a hallmark of Th2 (anti-inflammatory) response (Schonemeyer et al., 2001). C. elegans cystatins induced only the production of the Th1 cytokines (TNF- $\alpha$, IL-12) of human PBMC (Schierack et al., 2003). In this regard, C. elegans cystatins had an effect similar to that of chicken cystatin (Das et al., 2001). The molecular basis for these differing effects are currently unclear.

The most obvious difference between filarial cystatins and cystatins of $C$. elegans was seen in experiments on the proliferative capacity of $\mathrm{T}$ cells. While the filarial cystatins of O. volvulus or Acanthoheilonema viteae interfered with the proliferation of human or murine T cells, C. elegans cystatins had no inhibiting effect (Schierack et al., 2003). Inhibition of antigen presentation, as well as $\mathrm{T}$ cell proliferation, by filarial cystatins (Hartmann et al., 1997; Schonemeyer et al., 2001) contributes to parasite survival in the host.

It appears that cystatins of both parasitic and free-living nematodes differ substantially with regard to their immunomodulatory properties. This suggests that cystatins have evolved during co-evolution of the parasites and their hosts and acquired anti-inflammatory properties (Hartmann \& Lucius, 2003).

\section{Effects on inducible nitric oxide production}

Interestingly, cystatins of nematodes, both parasitic and free-living, share with other members of the cystatin superfamily the potential to upregulate the nitric oxide production of IFN- $\gamma$-activated macrophages (Verdot et al., 1996; Schierack et al., 2003). The upregulation of NO by application of chicken cystatin was potent enough to cure mice from potentially fatal visceral leishmaniasis (Das et al., 2001). Nitric oxide was also associated with suppression of antigen-specific $\mathrm{T}$ cell proliferation in a murine model of filariasis ( $\mathrm{O}^{\prime}$ Connor et al., 2000). Because filarial cystatins are strong inducers of NO, it is not excluded that they are indirectly linked to killing of microfilariae and inhibition of the $\mathrm{T}$ cell responses.

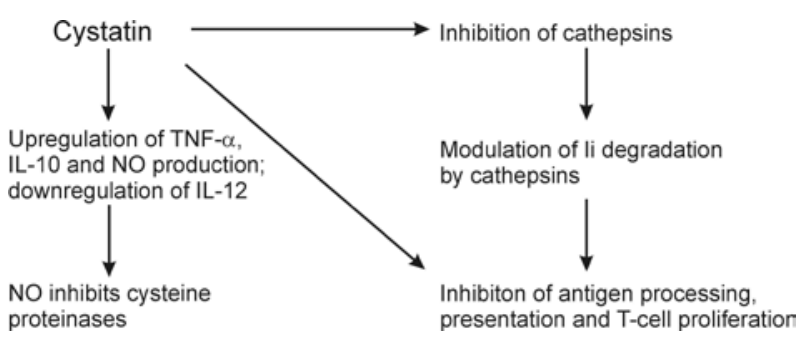

Figure 3. Simplified presentation of immunomodulatory action of nematode cystatins (based on Vray et al., 2002). $\mathrm{NO}$, nitric oxide; Ii, the MHC class II-associated invariant chain.

\section{Serine proteinase inhibitors}

Serine proteinase inhibitors are categorized according to primary sequence, structural motifs and mechanism of binding (Potempa et al., 1994). Serpins are large proteins, more than 100 of which have been identified in vertebrates, insects, plants and viruses (Marshall, 1993). In mammals, they are key regulatory proteins involved in essential extracellular functions such as complement activation, fibrinolysis, coagulation and inflammation (Potempa et al., 1994). In helminth genome, sets of serine proteinase inhibitor genes (available from accessible databases) are found in C. elegans, many parasitic nematodes as well as the trematode Schistosoma (Zang \& Maizels, 2001; Table 3). Among them a novel, distinct family of smapins, small serine proteinase inhibitors (less than 100 amino-acid residues) was recognized (Table 3). The most striking characteristic of the smapin family is the universal presence of ten cysteine residues that form five disulfide bonds.

\section{Serpins}

Although nematode serpins have low overall homology to the serpins from mammalian species, their sequences are identical or conserved at most of the key amino-acid positions (Zang \& Maizels, 2001). In view of the key role that mammalian serpins play in the regulation of biological processes, one can imagine that pathogens might themselves encode serpins and use them to block host-defense functions. The only nematode serpin for which experimental evidence indicates an evasive function is Brugia malayi serpin-2 (Bm-SPN-2). It specifically inhibits two human neutrophil-derived serine proteinases, cathepsin G and elastase (Zang et al., 1999). It is interesting that $B m-S P N-2$ is expressed and secreted at a single point in the parasite life cycle by the blood-born microfilariae. The consequences of $\mathrm{Bm}$ SPN-2 inhibition in vivo have yet to be studied, but neutrophil-derived cathepsin $G$ is known to be an important chemokinetic stimulator of $\mathrm{T}$ lymphocytes and a chemoattractant for monocytes (Chertov et al., 1997). Schistosoma serpins are found either on or 
within the worm surface tegument and are present in higher-molecular-mass forms, indicating complex formation, perhaps with cognate proteinase (Ghendler et al., 1994). Schistosoma serpin, Smpi56, inhibits both schistosome and neutrophil elastase (Ghendler et al., 1994). Consequently, its role could include both the physiological control of elastase within the schistosomes, and protection of the parasite from activated neutrophils during inflammation. Physiological roles of $C$. elegans serpins have yet to be established. The assumption will be that their primary role is the regulation of endogenous serine proteinases (Zang \& Maizels, 2001).

Smapins

The role of smapin molecules has been clarified in two distinct parasite systems. In Ascaris, a parasitic nematode that resides within the human and pig intestinal tract, smapins protect the worm from proteolytic degradation by the host's digestive enzymes (Martzen et al., 1985). These inhibitors are located at the surface of the developing eggs, larvae and the epithelial surface of the worm's own gut, combining with host proteinases to form inactive enzyme-inhibitor complexes. It is possible that this mechanism not only protects Ascaris within the degradative environment but could also mask the surface of developing larvae, permitting them to evade the host's immune system as they migrate from the intestine to the liver and lungs. In hookworms, the smapins are responsible for the long-known anticoagulant properties of these blood-feeding parasites. In this respect three smapins have been identified in the dog hookworm Ancylostoma caninum (Capello et al., 1995). Each inhibitor specifically inhibits a different range of blood coagulation serine proteinases (Stassens et al., 1996). Thus the strategy of $A$. caninum to interfere with mammalian blood coagulation pathway is distinct from those used by other hematophageous parasites or the mammalian host (reviewed in Zang \& Maizels, 2001). Two smapins: trypsin/chymotrypsin inhibitor, Ts-TCI, and chymotrypsin/elastase inhibitor, Ts-CEI, were purified from the adult stage of Trichuris suis, an intestinal parasite of swine. Ts-CEI inhibits chymotrypsin, pancreatic and neutrophil elastases, chymase (mouse mast cell proteinase-1, mMCP-1) and cathepsin G (Rhoads et al., 2000). The serine proteinase inhibitors of $T$. suis may function as components of the parasite defense mechanism by modulating intestinal mucosal mast cell-associated, proteinase-mediated, host immune response (Rhoads et al., 2000). In addition, the serine proteinase inhibitor "taeniastatin", isolated from the larval stage of the cestode Taenia taeniaeformis, has long been known to inhibit endogenous IL-1 and IL-2 production of murine lymphocytes, presumably in order to escape host immune defense (Leid et al., 1986).
These serine proteinase inhibitors are phylogenetically ancient, as inhibitors from $T$. suis share some similarity of sequence with proteinase inhibitors from other nematodes: Anisakis simplex, Ascaris suum (Rhoads et al., 2000; Table 3) as well as insects and amphibians (Rhoads et al., 2000).

\section{Helminth aspartic proteinase inhibitors: aspins}

These inhibitors have been identified in several parasitic nematodes and C. elegans. The structural features common to nematode aspins include the presence of a signal peptide sequence and conservation of all four cysteine residues in the mature protein (Shaw et al., 2003). The function of aspins is unclear. Ov33 from O. volvulus (Tume et al., 1997) and PI-3 from Ascaris suum (Martzen et al., 1990; Kageyama, 1998) inhibit the in vitro activity of aspartic proteinases such as pepsin and cathepsin E. PI-3 from Ascaris has been suggested to protect against digestion by host proteinases in the stomach and thus could enhance the survival of infective larvae. However, an Ancylostoma aspartic proteinase inhibitor-1, Ac-API (Delaney et al., 2005) as well as the proteinase inhibitor Tco-API-1 of another parasite of alimentary tract Trichostrongylus colubriformis did not inhibit the activity of porcine pepsin (Shaw et al., 2003). More likely, Ac-API functions as an inhibitor of an endogenous aspartic proteinase. Several nematodes possess non-lysosomal aspartic proteinases that are detected in excretory/ secretory products (Jolodar \& Miller, 1998; Geldhof et al., 2000) and may be secreted as inactive complexes with their appropriate aspartic proteinase inhibitors. Dissociation of the inhibitor would presumably activate the proteinase. As Ac-API is transcribed at all stages of development, and is released in excretory/secretory products of the adult, it would interact with the host immune system. Nematode APIs have been suggested to evoke Th2 immune responses in hosts, as O. volvulus aspin, Ov33 induced IgE and IgG4 antibodies production (Garraud et al., 1995). Considering the finding of a pronounced inhibitory activity against cathepsin E (Kageyama, 1998) this might be an important target in vivo. Cathepsin $\mathrm{E}$ has long been implicated as playing an important role in the processing of exogenous antigens for presentation to cells of the immune system on class II MHC proteins (expressed on the surface of an antigen presenting cells) (Bennett et al., 1992; Riese \& Chapman, 2000).

\section{ACETYLCHOLINESTERASES}

Acetylcholine is an important neurotransmitter in both free-living and parasitic nematodes and 
is associated with the neuromuscular system. The classical role of acetylcholinesterase (AchE) is to terminate transmission of neuronal impulses by rapid hydrolysis of acetylcholine. Cholinesterases secreted by many parasitic nematodes of (predominantly) the alimentary tract or other mucosal tissues are true acetylcholinesterases when analyzed by substrate specificity, inhibitor sensitivities and primary structure (reviewed in Lee, 1996). In the first two respects, they resemble vertebrate acetylcholinesterases, whereas the somatic (and therefore presumably neuronal) enzymes of nematodes analyzed to date display enzymatic properties similar to those of other invertebrate acetylcholinesterases (reviewed in Lee, 1996).

The amount of secreted enzymes varies from species to species, and between the sexes, it can also vary from larvae to adults. The isoenzyme pattern of acetylcholinesterase could change during the course of the infection as it has been shown for Nippostrongylus brasiliensis (reviewed in Lee, 1996). The reasons for those changes are not known. Possibly, by changing the form of the secreted AChEs the nematode is able to evade the action of antibodies directed against the earlier forms of the secreted enzyme (reviewed in Lee, 1996).

\section{Influence on intestinal peristalsis}

Certain species of nematodes that inhabit the alimentary system of animals can affect contractions of the wall of the alimentary tract and alter the movement of gut contents along the tract (Lee \& Foster, 1995). Thus, it was reasonable to conclude that the parasite's AChE could act as a "biochemical holdfast" enabling the nematodes to stay in their preferred site and that earlier-mentioned protective antibodies would inhibit this holdfast mechanism. However, Foster et al. (1994) have shown that AChE from the electric eel does not affect the amplitude of contractions of uninfected rat intestine segments maintained in vitro, as does supernatant of homogenates and ES from adult Nippostrongylus. It would appear that ES products of Nippostrongylus contain a vasoactive intestinal polypeptide-like protein (VIPlike protein) (Lee \& Foster, 1995; Foster \& Lee, 1996). Its mammalian homologue directly inhibits intestinal smooth muscle (Bitar \& Makhlouf, 1982) and VIP-ergic neurons are important inhibitory neurons in the gastrointestinal tract of mammals (Costa \& Furness, 1983).

\section{Influence on intestinal transport processes}

It is well known that the enteric nervous system does not simply regulate smooth muscle contraction, but is intimately involved in the control of transport processes in enterocytes. Thus, according to a model for cholinergic signaling in the intestinal mucosa, acetylcholine released from enteric cholinergic motor neurons stimulates chloride secretion (Cooke, 1984), mucus secretion (Specian \& Neutra, 1980), and Paneth cell exocytosis through muscarinic receptors (Satoh et al., 1992). It is likely that these secretory events contribute to expulsion of pathogens. Fluid and mucus secretion are stimulated during infection with nematode parasites. It is therefore an attractive proposition that AChEs secreted by nematode parasites of the gastrointestinal tract act to inhibit secretory responses by hydrolyzing acetylcholine released from the enteric nervous system (Selkirk et al., in Kennedy \& Harnett, 2001). It was shown that the expression of muscarinic acetylcholine receptors increased progressively on cells in the lamina propria after entry of $N$. brasiliensis parasites into rat jejunum (Selkirk et al., in Kennedy \& Harnett, 2001). These alterations in receptor expression may provide a lead to understanding the reasons for acetylcholinesterase secretion by parasitic nematodes.

\section{Immunomodulation}

It has been suggested that one of the functions of acetylcholinesterases secreted by the nematodes is to modulate the immune system of the host (Rhoads, 1984; Pritchard et al., 1993). Acetylcholinesterase produced by nematodes, such as Haemonchus and Ostertagia that inhabit the stomach or abomasum, might reduce inflammation and local ulceration by hydrolyzing acetylcholine which stimulates gastric acid secretion. Acetylcholine has been recorded to have numerous effects on leukocytes, including stimulation of chemotaxis and lysosomal enzyme secretion by neutrophils, inflammatory mediators, histamine and leukotriene release by mast cells, and augmentation of lymphocyte-mediated cytotoxicity (reviewed in Lee, 1996). Plasma cells can respond to acetylcholine by increasing secretion of immunoglobulins (Brink et al., 1994). Thus, acetylcholinesterase activity would help to prevent stimulation of cellular and humoral response to parasite infection.

In conclusion, the function of the secreted enzymes remains undefined, but may be related to the regulation of physiological responses that promote expulsion of parasites by cholinergic elements of the enteric nervous system or to the modulation of the host's inflammatory and/or immune response.

\section{MUCINS}

Invasion of Toxocara canis occurs in all mammalian species, but only in canid hosts do larvae 
progress along a typical ascarid nematode developmental pathway. In other hosts the larvae remain in the tissue-migratory phase (for even 9 years after infection) without ever developing. The ability of arrested-stage larval parasites to survive in the tissues for many years must depend on potent immune-evasive and anti-inflammatory mechanisms operated by the parasite. Toxocara has an exceptional ability to withstand attack by the immune system, most probably due to specific glycoproteins that are found in secretory glands and on the surface of the parasite. The external surface of the T. canis larva is covered by a carbohydrate-rich surface coat, which is a common feature of nematodes, both parasitic and free-living (Maizels \& Loukas in Kennedy \& Harnett, 2001). The surface coat appears to play a primary role in immune evasion, as it is shed when the parasite is bound by granulocytes or antibodies. A principal class of surface coat molecules are secreted mucins, MUC-1, MUC-2 and MUC-3 (Maizels \& Loukas in Kennedy \& Harnett, 2001). Mucins are large glycoproteins characterized by high charge density from sialic acid and surface residues, as well as by proteinase resistance and hydration of molecules (Moncada et al., 2003). Adult worms of another nematode, Strongyloides venezuelenzis, secrete mucinlike substances which are a key component enabling the parasites to invade and establish in the host epithelial layer (Maruyama \& Nawa, 1997).

\section{LECTINS}

In helminths, several surface and/or secreted C-type lectins and S-type lectins (galectins) have been identified; they are speculated to play a role in immunomodulation, but their probable interaction with host immune cells remains hypothetical (Loukas \& Maizels, 2000), although the activation of immune cells by components from protozoan parasites has been well documented (Moncada et al., 2003).

C-type or $\mathrm{Ca}^{+}$-dependent lectins are a family of carbohydrate-binding proteins that bind carbohydrates which range from simple monosaccharides to complex glycoconjugates, in $\mathrm{Ca}^{+}$-dependent fashion (Weis et al., 1998). Lectins are involved in activation of innate immunity in both vertebrates and invertebrates. Helminth C-type lectins, sharing sequence and structural similarity with mammalian immune cell lectins, have recently been identified from $T$. canis larvae.

Arrested stage larvae secrete lectins: TES-32 and TES-70. TES-32 has been localized to the epicuticule of larval T. canis (Page et al., 1992). The Cterminal domain of TES-32 shows similarity to host immune lectins like macrophage mannose receptor, E-selectin, macrophage binding protein A (Lou- kas et al., 1999). TES-70 lectin binds to the surface of mammalian epithelial cells which suggests that host glycans, possibly those involved in immunity, are ligands for these TES lectins. It is hypothesized that secreted nematode C-type lectins might bind to selectin ligands that are up-regulated during tissue damage, and thus compete with L-selectin, inhibiting its binding to leukocytes. Lectins might inhibit infiltration of leukocytes to sites of inflammation by binding to ligands expressing sialyl-Lewis ${ }^{x}$ antigen (Loukas et al., 2000).

Hematophagous nematodes such as hookworms are often in intimate contact with the mucosa and lectins secreted at the site of attachment might dampen the local immune response during feeding. Anticoagulation of host blood is another potential role for C-type lectins secreted by bloodfeeding nematodes as it is known that snake venom contains C-type lectins that inhibit clotting of blood (Takeya et al., 1992). In accord, two cDNAs encoding C-type lectins have been identified from expressed sequence tags of the human hookworm Necator americanus (Daub et al., 2000) and Nippostrongylus brasiliensis (Harcus et al., 2004). Expressed sequence tags encoding C-type lectin-like proteins have been identified from Ancylostoma ceylanicum, Ascaris suum and Haemonchus contortus (reviewed in Loukas \& Maizels, 2000). All these genes share sequence similarity with mammalian immune cell lectins.

There is the good biochemical evidence for the presence of surface/secreted lectins at most stages of schistosome life cycle. These surface lectins might adsorb host antibodies and complement components (Tarleton \& Kemp, 1981), as well as MHC I class antigens, on their surface to avoid immune recognition (Simpson et al., 1983). Thus host lectins are required to bind to carbohydrate "danger" signals in order to initiate inflammatory influx around the parasite, and the release of a parasite lectin may block this process. Recently, Sm60, a mannose-binding protein from S. mansoni, was recovered from adult worm tegument and cercariae. Sm60 induced in vitro migration of human neutrophils and degranulation of mast cells (Coelho-Castelo et al., 2002).

\section{PHOSPHORYLCHOLINE}

Phosphorylcholine (PC) is a structural component of a variety of prokaryotic and eukaryotic pathogens that also has immunomodulatory properties. In bacteria, it was found to be associated with a polysaccharide component of the cell wall and cell membrane (reviewed in Harnett et al., 2003). Both in prokaryotes and eukaryotes, PC is attached directly to sugar residues (reviewed in Harnett \& Harnett, 1999). Some species of nematodes as filariae 
(reviewed in Harnett \& Harnett 1999) or T. spiralis (Takahasi et al., 1993) contain PC on their cuticle. PC is also a component of certain glycoproteins actively secreted by filarial nematodes. One of these molecules, ES-62, is a major secreted glycoprotein of the rodent filarial nematode Acanthocheilonema viteae (Harnett et al., 1989), and another homologue of ES-62 is produced by the feline filarial nematode Brugia pahangi (Nor et al., 1997) and Onchocerca spp. (Haslam et al., 1999) and has been found in expressed sequence tags in the human filarial nematode Brugia malayi (Stepek et al., 2004). The amino-acid sequence of ES-62 shows $37-39 \%$ identity with a family of six other proteins, some of which have been predicted to be amino- or carboxypeptidases. ES-62 has been shown to possess a weak aminopeptidase activity in vitro against synthetic substrates (Harnett et al., 1999).

\section{Interaction of immune system cells with phospho- rylcholine-containing molecules}

The glycoprotein ES-62 is able to interact with a number of immune system cells, specifically with B- and T-lymphocytes, macrophages and dendritic cells. Cells expressing PAF receptor (known to interact with the phosphorylcholine moiety of PAF) are able to interact with phosphorylcholine-containing bacteria. The interaction can be blocked by PAF-receptor antagonists and such antagonists can prevent bacteria-induced pneumonia in mice (Cundell et al., 1995). Our unpublished results show that phosphorylcholine antigens of $T$. spiralis exert their effect through the PAF receptor. We observed that specific blocking of alveolar macrophage PAF receptors with an antagonist (CV 6209) prevented oxidative burst evoked by homogenates derived from $T$. spiralis newborn as well as muscle larvae.

Peritoneal macrophages pre-exposed to ES62 have impaired production of IL-12, IL-6 and TNF- $\alpha$ following subsequent stimulation with IFN$\gamma$ and LPS (reviewed by Harnnett et al., 2003). The PC component of filarial nematode extracts was shown to induce IL-10 production in peritoneal B-1 cells (Palanivel et al., 1996). On the other hand, PCcontaining glycosphingolipids from Ascaris suum were found to inhibit IL-12 production by peritoneal macrophages of mice (Deehan et al., 2002). The reduced production of Th1-inducing cytokine IL-12, as well as pro-inflammatory TNF- $\alpha$ and IL6 , biases immune responses towards the Th2/antiinflammatory phenotype. Likewise, dendritic cells, which mature in the presence of ES-62, acquire a phenotype allowing them to induce anti-inflammatory, Th2-type responses (reviewed by Harnnett et al., 2003).
Lymphocytes exposed to ES-62 both in vitro and in vivo are less able to proliferate in response to ligation via the antigen receptor. Studies of the interaction of ES-62 in lymphocytes show that it is associated with activation of certain signal transduction molecules, including a number of protein tyrosine kinases and mitogen activated protein kinases (MAP kinases). Whereas such activation is insufficient to induce proliferation, it serves to almost completely desensitize the cells to activation of phosphoinositide 3-kinase (PI-3-kinase) and Ras/MAP kinase pathways by antigen-receptor ligation, events critical for lymphocyte proliferation. Such desensitization reflects ES-62-primed recruitment of a number of negative regulators of these pathways, such as the phosphatases SHP-1 and Pac-1 (reviewed by Harnnett et al., 2003).

\section{NEMATODE NUCLEOTIDE-METABOLIZING ENZYMES}

Tissue damage results in a variety of molecular signals that activate elements of the immune system. Key regulators of these events are extracellular nucleotides that signal through purinergic receptors. Nucleotides may be secreted in a regulated manner or released upon mechanical stimulation, whereas tissue damage results in their massive release into extracellular fluids. In hematopoietic cells, signaling through nucleotide receptors stimulates a multitude of responses of the innate immune system (Linden, 2001; Hasko \& Cronstein, 2004). Hematophagous insects and ticks secrete enzymes in their saliva that degrade nucleotides, thus inhibiting hemostasis and minimizing the ensuing pain and inflammatory reactions provoked by these mediators (reviewed in Gounaris \& Selkirk, 2005). The discovery of an enzymatic cascade of nucleotide-metabolizing enzymes in secreted products of $T$. spiralis suggests that endoparasites use similar mechanisms to modulate host purinergic receptor signaling (Fig. 4).

Recently, T. spiralis has been shown to secrete nucleoside diphosphate kinase, 5'-nucleotidase and adenosine deaminase (Gounaris, 2002; Gounaris et al., 2001). The 5'-nucleotidase of $T$. spiralis exhibits unique properties in catalyzing the hydrolysis of nucleoside $5^{\prime}$-diphosphates in addition to nucleoside 5'-monophosphates, but shows no activity against nucleoside 5'-triphosphates (Gounaris et al., 2004; Fig. 4). Close homologues of this enzyme are present in the Trichuris muris expressed sequence tag dataset (Gounaris \& Selkirk, 2005). Apyrase (nucleoside triphosphate dephosphorylase), 5'-nucleotidase and nucleoside diphosphate kinase activities were identified in secreted products of Nippostrongylus brasiliensis (Gounaris \& Selkirk, 2005) and nucleoside 
(a)

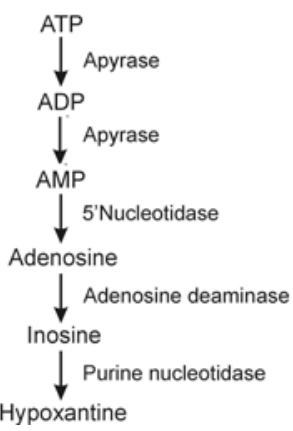

(b) Protein phosphorylation

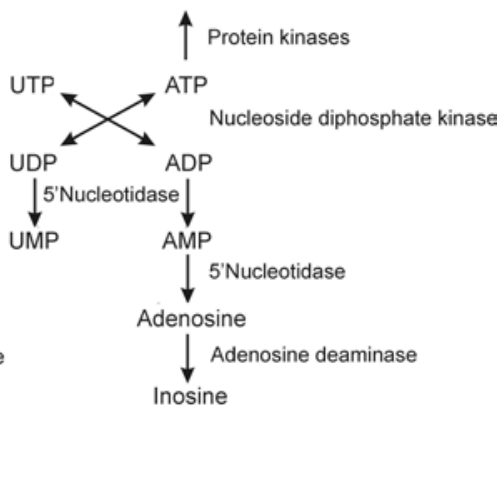

Figure 4. Cascades of enzymes metabolizing nucleotides. (a) The saliva of hematophagous insects; (b) excretory/ secretory products of Trichinella spiralis (modified from Gounaris \& Selkirk, 2005).

diphosphate kinase was found in the secreted products of Haemonchus contortus (Yatsuda et al., 2003). It therefore appears likely that secretion of nucleotidemetabolizing enzymes is exhibited by a variety of nematode species.

Both adenosine and inosine exhibit potent immunomodulatory effects (reviewed by Gounaris \& Selkirk, 2005). Metabolism to inosine might be advantageous to an invasive organism because it would shorten the action of adenosine, which apart from inhibition of platelet aggregation and vasodilatory activity, which is of benefit to hematophagous species (Biaggioni, 2004), promotes chemotaxis, activation, and degranulation of mast cells (McCloskey et al., 1999; Linden, 2001). These cells are important gastrointestinal effectors against intestinal nematodes (Knight et al., 2000; McDermott et al., 2003). A major difference between the nucleotide-metabolizing enzymes secreted by hematophagous arthropods and those of T. spiralis is the absence of ATP-ase in T. spiralis. This is significant as, in addition to proinflammatory effects, mast cell degranulation (Di Virgilio et al., 2001), ATP, UTP and UDP stimulate chloride secretion in epithelial cells, and mucus secretion from goblet cells (Bucheimer \& Linden, 2004). This type of response is unfavorable for intestinal parasite, as epithelial chloride flux drives net fluid secretion, which clears the intestinal tract (Cooke et al., 2003). However, T. spiralis secretes a nucleoside diphosphate kinase (Gounaris et al., 2001) which would convert ATP to ADP or UTP to UDP in the presence of suitable nucleoside phosphate acceptors. Inactivation of UDP by the nucleotidase would act against fluid secretion contributing to parasite expulsion.

As it appears, secretion of nucleotide-metabolizing enzymes by both ecto- and endoparasites would be advantageous not only to hematophagous species, but also to those species that through tissue damage or residence in the vascular system might promote platelet aggregation and subsequent release of proinflammatory nucleotides. This might therefore prove to be a conserved and underappreciated feature of many infectious organisms, including bacteria (Zaborina et al., 1999), with important consequences for pathogenicity.

\section{PROTEINS SECRETED BY THE INTRACELLULAR METAZOAN PARASITE TRICHINELLA SPIRALIS}

Trichinella spiralis infective larvae secrete many enzymes of poorly characterized functional properties. T. spiralis is an intracellular parasitic nematode capable of transforming striated muscles of mammals into a new syncytium known as a nurse cell complex. Besides its multinucleated structure, the nurse cell bears no morphological or biochemical similarity to the uninfected muscle (Stewart, 1983). Infection of skeletal muscle cells leads to the cell cycle re-entry and arrest at the G2/M phase boundary, and to a novel cellular phenotype (Jasmer, 1993; 1995). The structural and regulatory muscle genes are down regulated at the transcriptional level and the muscle differentiation program is inactivated in the nurse cell (Jasmer, 1993). However, the molecular mechanisms involved in host cell reorganization are unknown. Excretory/secretory products of infective larvae have been detected in the cytosol and nuclei of infected muscle cells (Despommier et al., 1990; Lee et al., 1991), and are also secreted into epithelial cells of intestinal mucosa (Capo et al., 1986) where the nematode is believed to moult, mature and reproduce (Gardiner, 1976). Thus the products secreted by $T$. spiralis infective larvae might also play a role in the process of infection of enterocytes. The mechanism of cellular invasion by $T$. spiralis is still unknown, and the role of secreted or surface bound proteins with respect to invasion and survival of the parasite in either skeletal muscle or intestinal epithelia remains largely uninvestigated.

\section{Protein kinases and phosphatases}

These enzymes are known to affect a variety of cellular signaling processes (Redegeld et al., 1999). The vast majority of protein kinases are intracellular; extracellular protein kinases are quite rare (Ehrlich \& Kornecki, 1987) but ecto-protein kinase and phosphatase activities have been identified on a variety of cells (Walter et al., 1996; Petitfrere et al., 1996) and parasitic protozoans Leishmania and Trypanosoma spp. Infective larvae of $T$. spiralis have externally oriented enzymes catalyzing reversible protein phosphorylation on their surface (Smith et al., 2000). Both serine/ threonine and tyrosine phosphorylation and dephos- 
phorylation of secreted and membrane bound parasite proteins was reported to take place at the infective larvae surface. Among phosphorylated proteins a major species of $45 \mathrm{kDa}$ was observed only after bile treatment (Smith et al., 2000). Thus, it is believed that this protein may be involved in some recognition of the activation process in the enteral phase of infection. An integral membrane protein with serine/threonine kinase activity has been detected on the surface of the trematode S. mansoni, although its catalytic domain is predicted to be cytoplasmic. As the protein is homologous to the TGF- $\beta$ receptor family, it presumably acts to transduce signals by an unidentified ligand (Davies \& Pearce, 1995). Apart from these ecto-enzymes, $T$. spiralis larvae secrete at least two distinct serine/threonine protein kinases of 70 and $135 \mathrm{kDa}$, which almost exclusively phosphorylate a protein doublet at 50-55 $\mathrm{kDa}$ from ES products (Arden et al., 1997). These protein kinases could not be readily assigned to any of the major documented subfamilies of serine/threonine protein kinases. In connection with externally occurring protein phosphorylation, the earlier mentioned lack of ATPase in ES products of T. spiralis might therefore be essential for the efficient activity of protein kinases (Smith et al., 2000). Of the proteins possibly important for muscle cells, MyoD, one of the family of muscle-specific transcriptional regulators (Weintraub, 1993) is phosphorylated by T. spiralis protein kinases in vitro, but according to Arden et al. (1997) it is premature to assign any physiological significance to this observation.

\section{Endonucleases}

The ES products of Trichinella spiralis contain double-stranded endonuclease which can recognize host muscle cells (Mak \& Ko, 1999). Similar to the T. spiralis enzyme, endonucleases have been characterized from the slime mould Dictyostelium discoideum and the insectivorous plant Drosera adelae (Guyer et al., 1985; Okabe et al., 1997). However, the biological significance of both endonucleases is still not known, thus the role of the T. spiralis endonuclease for the parasite is speculative (Mak \& Ko, 1999). As double-stranded endonuclease was detected only in T. spiralis and not in T. pseudospiralis, this may be correlated with the difference in pathogenesis caused by the two worms: $T$. spiralis causes a drastic reorganization of muscle cells leading to the establishment of the nurse cell, whereas T. pseudospiralis does not. Mak and Ko (1999) believe that the occurrence of the endonuclease only in the worm which can form nurse cells may suggest that the molecule plays a crucial role in host cell recognition. Further, there are numerous reports showing that persistent double stranded breaks in chromosomal DNA would not only destabilize DNA (accounting for genomic changes), but could also lead to the arrest of the cell cycle at the G2 phase, and eventually cell death (Bennett et al., 1997; ap-Rhys \& Bohr, 1996). Possibly, the secreted endonuclease may be involved in the arrest of $T$. spiralis infected muscles at the G2/M phase of the cell cycle (Jasmer, 1993). Therefore, there is good likelihood that one of the major functions of the endonuclease of $T$. spiralis is to control the cell cycle (Mak \& Ko, 1999).

Besides the double-stranded endonuclease, a non-specific, single-stranded endonuclease in the ES products of T. spiralis and T. pseudospiralis was found (Mak et al., 2000). The biochemical properties of the single-stranded endonuclease of Trichinella differ from those of other well-characterized endonucleases (Mak et al., 2000). Significant differences (especially in molecular mass, cation dependence, and species-specific expression) occur between the single and double-stranded endonucleases of Trichinella. According to the authors' suggestion, the two endonucleases may play a distinct role in the reorganization of host tissues or in pathogenesis. Moreover, the expression pattern of the singlestranded endonuclease suggests that it may have a more general role as in viruses and bacteria (discussed in Mak et al., 2000). In Mycoplasma penetrants single-stranded endonuclease degrades host nucleic acids to acquire the precursors for nucleic acid biosynthesis, leading to chromosomal alterations (Bendjennat et al., 1997).

\section{DNA-binding activity}

A DNA-binding peptide of $30 \mathrm{kDa}$ was documented in the excretory/secretory products of the infective-stage larvae of T. pseudospiralis (Mak \& Ko, 2001). This peptide could bind to the target DNA as a dimer, tetramer or multiples of tetramers with a low specificity. Similar activities were also observed in the ES products of $T$. spiralis. Since a DNA-binding protein has not been reported previously in parasitic organisms, one can only speculate on its possible functions. The occurrence of a DNA-binding peptide in both T. spiralis and T. pseudospiralis may point to its crucial role in the reorganization of host cells by trichinellids. The lack of specificity of the protein may facilitate the binding to DNA of myonuclei of all mammalian or avian species (Mak \& Ko, 2001). In the case of an intracellular protozoan parasite, Theileria annulata, a putative parasite-encoded factor, Tash AT2, which modulates the host gene expression, has been identified. The protein contains three AT hook DNA-binding domains and is located in the host cell nucleus (Swan et al., 1999). This provides the important evidence that factors can be transported from the parasite to the host nucleus 
and bind host DNA. A similar event can also occur in trichinellosis (Mak \& Ko, 2001).

\section{Saposins}

Saposins or sphingolipid activator proteins (SAPs) function as non-enzymatic cofactors for the hydrolysis of sphingolipids in lysosomes. Four of the five known members of this class (SAP-A to SAP-D), originally defined in vertebrates, are synthesized as a precursor termed prosaposin, which is proteolytically cleaved to generate four homologous glycoproteins having the molecular mass of approx. $11 \mathrm{kDa}$ (Schuette et al., 2001). Saposins facilitate the interaction between water-soluble hydrolytic enzymes and their membrane-bound substrates. The function of the mammalian secreted prosaposin has not been established, although it retains most of the activating properties of the mature saposins (Kishimoto et al., 1992). Moreover, prosaposin binds several glycolipids and can facilitate their insertion into membranes (Soeda et al., 1993).

Recently, it has been shown that infective larvae and adult specimens of Trichinella spiralis secrete a full-length prosaposin in an unprocessed form (Selkirk et al., 2004). The secreted protein most probably originates from stichocytes or intestinal cells. It is possible that the parasite prosaposin facilitates invasion of intestinal epithelial cells and subsequent migration through this cell layer. The saposin-like protein family comprises pore-forming peptides, which have been identified in a variety of organisms. Among parasitic metazoans pore forming peptides have been found to be expressed stage specifically in juvenile and adult flukes of Fasciola hepatica and Clonorchis sinensis (Reed et al., 2000; Lee et al., 2002) and localized in the intestinal epithelium of adult flukes (Lee et al., 2002). Hemolytic activity has been found in extracts from two blood-feeding nematodes Haemonchus contortus and Ancylostoma caninum (Fetterer \& Rhoads, 1997a; Don et al., 2004). It is tempting to suggest that the secreted peptide or protein hemolyzes the host blood cells ingested by the parasites and releases the host cellular components into the parasite intestinal lumen, making them accessible to digestive enzymes of those worms (cf. Fig. 1).

\section{ANTIOXIDANT ENZYMES SECRETED BY HELMINTHS}

All aerobic organisms require protection mechanisms that limit molecular damage caused by reactive oxygen species (ROS) such as superoxide anion radical $\left(\mathrm{O}_{2}^{-\bullet}\right)$, hydrogen peroxide $\left(\mathrm{H}_{2} \mathrm{O}_{2}\right)$ and hydroxyl radical $\left(\mathrm{OH}^{*}\right)$. ROS are always generated during cellular metabolism. In addition, parasitic or- ganisms need protection against ROS that arise from infection-stimulated host phagocytes (neutrophils and macrophages) (Cross \& Jones, 1991) as a part of innate mechanisms of defense.

Enzymes dealing with superoxide anion radical, superoxide dismutases (Fig. 5), which catalyze the dismutation of superoxide radicals into hydrogen peroxide and oxygen have been described in every species of parasitic helminths examined (reviewed in James, 1994), whereas enzymes that deal with hydrogen peroxide have been difficult to identify. The control of $\mathrm{H}_{2} \mathrm{O}_{2}$ levels is essential, as $\mathrm{H}_{2} \mathrm{O}_{2}$ leads to the formation of $\mathrm{OH}^{\bullet}$ for which no specific scavenger exists, due to its extreme reactivity. Therefore, the best way to control the $\mathrm{OH}^{\bullet}$ levels is the defense against $\mathrm{H}_{2} \mathrm{O}_{2}$ and $\mathrm{O}_{2}^{-\bullet}$. One class of enzymes capable of this function in mammals are selenium-containing glutathione peroxidases. These enzymes catalyze the reduction of $\mathrm{H}_{2} \mathrm{O}_{2}$ and organic hydroperoxides along with oxidation of glutathione (GSH) to glutathione disulfide (Henkle-Dührsen \& Kampkötter, 2001). However, they appear to be absent in parasitic nematodes (Callahan et al., 1988), although a selenium-independent glutathione peroxidase family exists. These selenium-independent enzymes have low or no activity with hydrogen peroxide. A second class, catalases metabolizing hydrogen peroxide into molecular oxygen and water, have been detected with low activity in most parasitic species but sequences encoding a typical catalase polypeptide have only been identified in a few species of nematodes such as Haemonchus contortus

\section{Superoxide dismutase}

$\mathrm{O}_{2}+\mathrm{O}_{2}+2 \mathrm{H}^{*} \longrightarrow \mathrm{H}_{2} \mathrm{O}_{2}+\mathrm{O}_{2}$

\section{Catalase}

$2 \mathrm{H}_{2} \mathrm{O}_{2} \longrightarrow 2 \mathrm{H}_{2} \mathrm{O}+\mathrm{O}_{2}$

Glutathione peroxidase

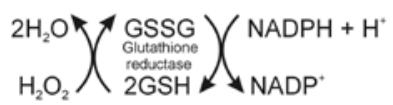

1-Cys peroxiredoxin

$\left.\begin{array}{l}2 \mathrm{H}_{2} \mathrm{O} \\ \mathrm{H}_{2} \mathrm{O}_{2}\end{array}\right)\left(\begin{array}{l}\mathrm{PRX}-\mathrm{S}-\mathrm{S} \\ \mathrm{PRX}(\mathrm{SH})_{2}\end{array}\right)\left(\begin{array}{l}\text { Reduced DTT } \\ \text { Oxidized DTT }\end{array}\right.$

2-Cys peroxyredoxin $=$ thioredoxin peroxidase

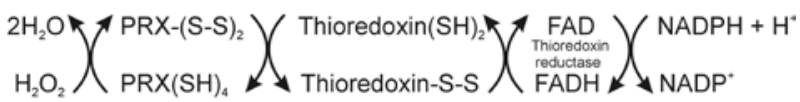

Glutathione S-transferase

$\mathrm{RX}+\mathrm{GSH} \longrightarrow \mathrm{GSR}+\mathrm{HX}$

Figure 5. Antioxidant enzymes secreted by helminths. GSSG, oxidized glutathione; GSH, reduced glutathione; DTT, dithiothreitol; PRX, peroxiredoxin; RX, xenobiotics, electrophiles. 
(Kotze \& McClure, 2001) or Ascaris suum (Eckelt et al., 1998), and a high level of catalase activity was documented in somatic extracts of B. malayi (Ou et al., 1995).

However, a new family of enzymes has recently been described, the peroxiredoxins (Chae et al., 1994b) (Fig. 5) that are probably the major $\mathrm{H}_{2} \mathrm{O}_{2}$ detoxifying enzyme in parasitic nematodes as well as in many other pathogens (McGonigle et al., 1998). In parasitic nematodes, peroxiredoxins may play a pivotal role, since they appear to be both a major antioxidant enzyme and could also be involved in cellular signaling processes. The next paragraph will focus on the occurrence and localization of these new antioxidant enzymes in parasitic helminths.

\section{Peroxiredoxins}

The discovery of this enzyme system represents a major advance towards the understanding of how parasitic nematodes deal with both internal and environmental oxidative stress. Peroxiredoxins (PRXs) exist as homodimers. They share the property of reducing hydrogen peroxide to water and alkyl hydroperoxides to the corresponding alcohols and have been classified into two families: the 1-Cys and 2-Cys peroxiredoxins according to the presence of one or two highly conserved cysteine residues (Chae et al., 1994c).

The PRXs are distinct from other peroxidases in that they have no cofactors, such as metals or prosthetic groups. Experiments with a human 1-Cys peroxiredoxin suggest that Cys-47-SH is the site of oxidation and that the oxidized product (probably Cys-SOH) can be reduced back to cysteine by dithiothreitol (Kang et al., 1998), but the physiological donor has not been identified (Seo et al., 2000). The 2-Cys peroxiredoxins are thioredoxin peroxidases, which have been shown to reduce $\mathrm{H}_{2} \mathrm{O}_{2}$ with the use of electrons from the thioredoxin system. Reduction of hydroperoxides by 2-Cys enzymes is accompanied by the formation of an intermolecular disulfide bond which is subsequently reduced by electrons donated by thioredoxin. Thioredoxin is regenerated by the system of thioredoxin reductase and NADPH (Chae et al., 1994a) (Fig. 5).

It is worth to mention that the mammalian members of the PRX family are believed not to be simply back-up systems for glutathione peroxidase and catalase (Brigelius-Flohe, 1999) but in addition to eliminating potentially damaging ROS, they can play a role in signal transduction and gene expression due to alterations in ROS concentrations (Lim et al., 1998). In this respect, a trematode, S. mansoni, was shown to possess both bacterial-like (resistant to oxidative inactivation, important in regulating cell signaling pathways), and mamma- lian-like sensitive peroxiredoxins (Sayed \& Williams, 2004).

\section{Peroxiredoxins in parasitic helminths}

Antioxidant enzymes dealing with ROS originating from phagocytic cells must function near by host-pathogen interface, e.g., they must be secreted or presented on the surface of worms. The localization profiles of the peroxiredoxins indicate that these enzymes are active in dealing with both internal and external oxidative stress (reviewed in HenkleDührsen \& Kampkötter, 2001).

Schistosomes lack catalase and have relatively low levels of glutathione peroxidase (Mkoji et al., 1988; Mei \& LoVerde, 1997) but peroxiredoxin plays a major role in the antioxidant defence in Schistosoma mansoni (Kwatia et al., 2000). 2-Cys peroxiredoxin protein (thioredoxin peroxidase) was expressed in both male and female adult worms (Kwatia et al., 2000). Genes encoding two 2-Cys peroxiredoxins were identified in the expressed sequence tag data base of S. mansoni. These 2-Cys peroxiredoxins efficiently utilize reducing equivalents from both the thioredoxin and glutathione systems. The ability of schistosome peroxiredoxins to use alternative electron donors may reflect their presence in different cellular sites and emphasizes the significant differences in overall redox balance mechanisms between the parasite and its mammalian host (Sayed \& Williams, 2004). The role of peroxiredoxin in the antioxidant defense of $S$. mansoni is supported by the fact of thioredoxin expression by all mammalian stages of the schistosome life cycle. Thioredoxin is present in egg secretory products and may cooperate in facilitating the passage and survival of eggs across inflamed host tissues (Alger et al., 2002). Similarly, another trematode Fasciola hepatica does not express a catalase and presents little glutathione peroxidase activity (McGonigle et al., 1997), thus peroxiredoxin could be the major hydrogen peroxide-removing antioxidant in this parasite.

Peroxiredoxins have been found in several species of nematodes. The enzyme from the swine roundworm Ascaris suum was cloned and shown to be present in extracts of adult female worms, suggesting that the native Ascaris peroxiredoxin might act as a major antioxidant enzyme in A. suum (Tsuji \& Kasuga-Aoki, 2001). In Onchocerca volvulus thioredoxin peroxidase was predominantly localized to the hypodermis and cuticle ( $\mathrm{Lu}$ et al., 1998). Peroxiredoxin was identified in parasite extracts and larval and adult excretory-secretory products of Dirofilaria immitis. The enzyme was localized to the lateral hypodermal chords of both female and male worms (Chandrashekar et al., 2000). Similar localization was demonstrated with the thioredoxin peroxidase- 1 of 
Brugia malayi (Ghosh et al., 1998). According to the opinion of these authors the apparent lack of an association of this enzyme with the surface or with excretory-secretory products of $B$. malayi does not preclude a role for thioredoxin peroxidase in countering radical attack from exogenous sources. Cuticle is easily permeable for radicals, so when they pass through, the first cells they would encounter would be those of the hypodermis-lateral chord. It is worth to note that one of the major surface-associated molecules of filarial nematodes is glutathione peroxidase (Cookson et al., 1992), being however, a selenium-independent enzyme.

\section{Level of antioxidant enzymes and parasite survival}

Effective protection of an invading parasite from host-produced ROS would depend on levels of scavenger enzymes in the invasive forms of the parasite. Studies on Nippostrongylus brasiliensis infection showed that the upregulation of superoxide dismutase, catalase, and glutathione peroxidase is correlated with persistence in the host. On the other hand, increased ROS production by peritoneal leukocytes has been correlated with the rejection of N. brasiliensis (Smith \& Bryant, 1989). The different degree of activities of anti-oxidant enzymes in Nippostrongylus brasiliensis and Nematospiroides dubius is correlated with the parasite's ability to survive in the host. $N$. brasiliensis adults are expelled from the small intestine in 10-12 days, whereas $N$. dubius adults persist for several months (Smith \& Bryant, 1989). N. dubius has 2-fold higher superoxide dismutase activity, and about 4-fold higher catalase and glutathione reductase activity than $N$. brasiliensis (Smith \& Bryant, 1989). It has been also demonstrated that Brugia malayi microfilariae and adults are relatively resistant to $\mathrm{H}_{2} \mathrm{O}_{2}$ (Ou et al., 1995) compared with the related filarial species Onchocerca cervicalis (Callahan et al., 1990) or Dirofilaria immitis (Rzepczyk \& Bishop, 1984). The susceptibility to $\mathrm{H}_{2} \mathrm{O}_{2}$ of both adults and microfilariae of $O$. cervicalis is correlated with small amounts of catalase and peroxidase in this species (reviewed in Callahan et al., 1988). Newly excysted juvenile flukes of Fasciola hepatica are relatively resistant to killing by free radicals in comparison to schistosomula of Schistosoma mansoni. This resistance could, in part, be due to the significant activity of oxidant-scavenging enzymes of newly excysted juvenile flukes (Piedrafita et al., 2000).

\section{Stage-specific expression of antioxidant enzymes and parasite survival}

The importance of antioxidant enzymes to the survival of $T$. spiralis has also been studied (Bass \& Szejda, 1979). It has been shown that superoxide dismutase is actively secreted by muscle larvae of T. spiralis cultured in vitro (Rhoads, 1983). Various developmental stages of $T$. spiralis contain different amounts of superoxide dismutase and glutathione peroxidase (Kazura \& Meshnick, 1984), correlating with the sensitivity of the organism to oxidant-mediated killing. Oxidant-resistant adult worms and muscle larvae had several times more of glutathione peroxidase and about four times more of superoxide dismutase than the oxidant-sensitive newborn larvae. Newborn larvae were partially protected against oxidant damage when mixed with adult worms. Similarly, newly excysted juvenile flukes of Fasciola hepatica expressed 2.5-20-fold lower levels of superoxide dismutase and glutathione $S$-transferase activity relative to immature or adult parasites. Incubation of newly excysted juvenile flukes with inhibitors of peroxidases and inhibitors of glutathione metabolism increased their killing by LPS-stimulated rat phagocytes (Piedrafita et al., 2000).

Studies of the developmental regulation of localization of glutathione peroxidase and superoxide dismutase in the trematode Schistosoma mansoni (Mei \& LoVerde, 1997) showed that these enzymes were found to be associated only with the adult tegument and gut epithelium. In Onchocerca volvulus, expression of thioredoxin peroxidase increased during differentiation to the infective L3 larva. This enzyme was also detected in post-infective larvae and adult worms. Its highly upregulated expression in infective larvae may aid in parasite establishment following transmission to the definitive host (Lu et al., 1998). In Brugia malayi glutathione peroxidase is expressed at negligible levels in mosquito-derived infective larvae, but after infection of the mammalian host, its synthesis is upregulated and the enzyme is transported to the cuticle (Devaney \& Jecock, 1991).

\section{ROS-induced changes in expression of helminth scavenger enzymes}

Zelck and Von Janowsky (2004) have shown that stage-dependent expression of superoxide dismutase, glutathione peroxidase, and glutathione $S$-transferase in Schistosoma mansoni is regulated at the transcriptional level. Generation of ROS by xanthine/xanthine oxidase resulted in increased transcript levels for all three enzymes. They compared influence of phagocytic cells of snails (schistosome intermediate hosts), susceptible and resistant to infection, on the level of the scavenger enzymes. It appeared that hemocytes from susceptible hosts induced higher levels of these enzyme expression in schistosome sporocysts, compared to hemocytes from resistant hosts. These results indicate that phagocytic cells of resistant snails may 
directly or indirectly downregulate schistosome antioxidant enzyme activity, thus facilitating killing of the parasite (Zelck \& Von Janowsky, 2004). This suggests that beside induction of scavenger enzyme transcription, snail phagocytes are able to modulate parasite antioxidant enzyme expression.

\section{Glutathione S-transferase}

This enzyme is involved in xenobiotic metabolism, intracellular binding, and biosynthesis of endogenous substrates, such as prostaglandins and leukotrienes (Boyer, 1989). Glutathione S-transferase isoenzymes which have very little homology with those from mammalian tissues have been found in helminths, such as trematodes and nematodes (reviewed in Rao et al., 2000). Immunohistochemical studies revealed that glutathione $S$-transferases in worms are predominantly associated with metabolic and reproductive sites of the organisms (reviewed in Rao et al., 2000). Glutathione S-transferases may potentially favor parasite survival by neutralizing the toxins acting against them and may repair hostinduced damage (Mitchell, 1989). In this respect T. spiralis glutathione transferase which functions as a selenium-independent glutathione peroxidase was detected by electron microscopy in the secretory organs (stichocytes) of L1 larvae. This enzyme seems to play a protective role against lipid peroxidation (Rojas et al., 1997).

In filarial nematodes the presence of selenium-independent glutathione peroxidase activity associated with nematode glutathione $S$-transferase has been described in D. immitis (Jaffe \& Lambert, 1986). In adult O. volvulus, one of the two identified isoenzymes of glutathione $S$-transferase has been found to be released by the worms (Liebau et al., 1994). Although glutathione $S$-transferase is ubiquitous in all stages of Brugia pahangi and B. malayi life cycle, a high activity of this enzyme was observed in L3 and L4 larvae (Rao et al., 2000). The elevated levels of glutathione $S$-transferase protein expression in Brugia larvae may be involved in the parasite's strategy for evasion, aimed at a host's early defense mechanisms, and may also assist in larval migration to the site of predilection (Rao et al., 2000). Glutathione $S$-transferase has been reported to be present on the body surface of the trematodes $S$. mansoni (Taylor et al., 1988) and F. hepatica (Wijffels et al., 1992).

Although the presented data points to the importance of antioxidant enzymes for the survival of some parasitic helminths, the role of the antioxidant enzymes in the host-parasite relationship may still be controversial for many other infectious metazoan species. It is obvious that those parasitic helminths which are able to utilize oxygen are absolutely dependent on their antioxidant defense system alone to deal with endogenously generated ROS. In essentially anaerobic tapeworms, such as adult $H$. diminuta and adult Moniezia expansa (the common tapeworm of sheep) no enzyme capable of metabolizing $\mathrm{H}_{2} \mathrm{O}_{2}$ such as catalase, lipoxygenase, glutathione peroxidase, NADH peroxidase, or NADPH peroxidase has been detected (reviewed in Callahan et al., 1988).

\section{CONCLUSIONS}

This review presents evidence that worms use many strategies to colonize a host and to stay in its organism. They secrete anti-oxidant enzymes which combat reactive oxygen species produced by the host phagocytic cells in response to parasitic infection. Nucleotide-metabolizing enzymes found in excretory/secretory products of nematodes could prevent platelet aggregation and the release of proinflammatory nucleotides. Secreted proteinases serve for digestion of the meal as well as for extracellular matrix degradation, which is necessary for tissue invasion. Proteinase inhibitors control proteinase activity. Secretion of proteinase inhibitors has a dual function. First, an inhibition of the host proteinase activity in order to defend against proteolysis by the host enzymes. Second, both proteinases and their inhibitors could take part in subverting the host immunological defense and polarizing the immunological response towards anti-inflammatory Th2. Although this response favors expulsion of gastrointestinal worms from the gut, generally parasites take advantages of the polarized Th2 response. Helminths produce homologues of cytokines possibly to influence the host defense. Some molecules such as phosphorylcholine containing ones, or cysteine proteinase inhibitors (cystatins), have been shown to interfere with the host immune cell signaling pathways. Different properties of cystatins from parasitic nematodes in respect to their free-living relatives suggest that they have acquired anti-inflammatory properties during co-evolution of the parasites and their hosts. The majority of molecules secreted by metazoan parasites have their homologues in other animals. These are universal molecules of crucial role in developing strategies of host invasion by parasites.

\section{Acknowledgements}

Many thanks to Dr. Małgorzata Skup for reading the manuscript and discussing its shape. Supported in part by the State Committee for Scientific Research, Grant No. 2 P05A 05626. 


\section{REFERENCES}

Abrahamson M (1994) Cystatins. Methods Enzymol 244: 685-700.

Adam R, Kaltmann B, Rudin W, Friedrich T, Marti T, Lucius $R$ (1996) Identification of chitinase as the immunodominant filarial antigen recognized by sera of vaccinated rodents. J Biol Chem 271: 1441-1447.

Alger HM, Sayed AA, Stadecker MJ, Williams DL (2002) Molecular and enzymatic characterization of Schistosoma mansoni thioredoxin. Int J Parasitol 32: 1285-1292.

ap-Rhys CM, Bohr VA (1996) Mammalian DNA repair responses and genomic instability. Experientia 77 (Suppl): 289-305.

Arden SR, Smith AM, Booth MJ, Tweedi S, Gounaris K, Selkirk ME (1997) Identification of serine/threonine protein kinases secreted by Trichinella spiralis infective larvae. Mol Biochem Parasitol 90: 111-119.

Arechavaleta F, Molinari JL, Tato P (1998) A Taenia solium metacestode factor nonspecifically inhibits cytokine production. Parasitol Res 84: 117-122.

Auriault C, Ouaissi MA, Torpier G, Eisen H, Capron A (1981) Proteolytic cleavage of IgG bound to the Fc receptor of Schistosoma mansoni schistosomula. Parasite Immunol 3: 33-44.

Bacher M, Metz CN, Calandra T, Mayer K, Chesney J, Lohoff M, Gemsa D, Donnelly T, Bucala R (1996) An essential regulatory role for macrophage migration inhibitory factor in T-cell activation. Proc Natl Acad Sci USA 93: 7849-7854.

Bass DA, Szejda P (1979) Mechanisms of killing of newborn larvae of Trichinella spiralis by neutrophils and eosinophils. Killing by generation of hydrogen peroxide in vitro. J Clin Invest 64: 1558-1564.

Bendjennat M, Blanchard A, Loutfi M, Montagnier L, Bahraoui E (1997) Purification and characterization of $\mathrm{Myc}$ oplasma penetrans $\mathrm{Ca}^{2+} / \mathrm{Mg}^{2+}$-dependent endonuclease. J Bacteriol 179: 2210-2220.

Bennett K, Levine T, Ellis JS, Peanasky RJ, Samloff IM, Kay J, Chain BM (1992) Antigen processing for presentation by class II major histocompatibility complex requires cleavage by cathepsin E. Eur J Immunol 22: 1519-1524.

Bennett CB, Snipe JR, Resnick MA (1997) A persistent double-strand break destabilizes human DNA in the yeast and can lead to G2 arrest and lethality. Cancer Res 57: 1970-1980.

Bernal D, de la Rubia JE, Carrasco-Abad Toledo R, MasComa S, Marcilla A (2004) Identification of enolase as a plasminogen-binding protein in excretory-secretory products of Fasciola hepatica. FEBS Lett 563: 203-206.

Biaggioni I (2004) Clinical and molecular pharmacological characteristics of adenosine induced vasodilatation. Clin Pharmacol Ther 75: 137-139.

Bitar KN, Makhlouf GM (1982) Relaxation of isolated gastric smooth muscle cells by vasoactive intestinal peptide. Science 216: 531-533.

Boyer TD (1989) The glutathione S-transferase: an update. Hepatology 9: 486-496.

Brigelius-Flohe R (1999) Tissue-specific functions of individual glutathione peroxidases. Free Radic Biol Med 27: 951-965.

Brink PR, Walcott B, Roemer E, Grine E, Pastor M, Christ GJ, Cameron RH (1994) Cholinergic modulation of immunoglobulin secretion from avian plasma cells: the role of calcium. J Neuroimmunol 51: 113-121.

Britton C, Murray L (2004) Cathepsin L protease is essential for yolk processing during embryogenesis in Caenorhabditis elegans. J Cell Sci 117: 5133-5143.
Brown A, Burleigh JM, Billett EE, Pritchard DI (1995) An initial characterization of proteolytic enzymes secreted by the adult stage of the human hookworm Necator americanus. Parasitology 110: 555-563.

Bucheimer RE, Linden J (2004) Purinergic regulation of epithelial transport. J Physiol 555: 311-321.

Callahan HL, Crouch RK, James ER (1988) Helminth antioxidant enzymes: a protective mechanism against host oxidants. Parasitol Today 4: 218-225.

Callahan HL, Crouch RK, James ER (1990) Hydrogen peroxide is the most toxic oxygen species for Onchocerca cervicalis microfilariae. Parasitology 100: 407-415.

Capo V, Silberstein D, Despommier DD (1986) Immunocytolocalization of two protection-inducing antigens of Trichinella spiralis during its enteral phase in immune and non-immune mice. J Parasitol 72: 931-938.

Cappello M, Vlasuk GP, Bergum PW, Huang S, Hotez PJ (1995) Ancylostoma caninum anticoagulant peptide: a hookworm derived inhibitor of human coagulation factor Xa. Proc Natl Acad Sci USA 92: 6152-6156.

Carmona C, Dowd AJ, Smith AM, Dalton JP (1993) Cathepsin L proteinase secreted by Fasciola hepatica in vitro prevents antibody-mediated eosinophil attachment to new excysted juveniles. Mol Bioch Parasitol 62: 9-18.

Chae HZ, Chung SJ, Rhee SG (1994a) Thioredoxin-dependent peroxide reductase from yeast. J Biol Chem 269: 27670-27678.

Chae HZ, Robison K, Poole LB, Church G, Storz G, Rhee SG (1994b) Cloning and sequencing of thiol-specific antioxidant from mammalian brain: alkyl hydroperoxide reductase and thiol-specific antioxidant define a large family of antioxidant enzymes. Proc Natl Acad Sci USA 91: 7017-7021.

Chae HZ, Uhm TB, Rhee SG (1994c) Dimerization of thiolspecific antioxidant and the essential role of cysteine 47. Proc Natl Acad Sci USA 91: 7022-7026.

Chandrashekar R, Tsuji N, Morales TH, Carmody AB, Ozols VO, Welton J, Tang L (2000) Removal of hydrogen peroxide by a 1-cysteine peroxiredoxin enzyme of the filarial parasite Dirofilaria immitis. Parasitol Res 86: 200-206.

Chapman CB, Mitchell GF (1982) Proteolytic cleavage of immunoglobulin by enzymes released by Fasciola hepatica. Vet Parasitol 11: 165-178.

Chertov O, Ueda H, Xu LL, Tani K, Murphy WJ, Wang JM, Howard OM, Sayers TJ, Oppenheim JJ (1997) Identification of human neutrophil-derived cathepsin G and azurocidin/CAP37 as chemoattractants for mononuclear cells and neutrophils. J Exp Med 186: 739-747.

Cho SY, Chung YB, Kong Y (1992) Component proteins and proteases activities in excretory-secretory product of sparganum. Korean J Parasitol 30: 227-230.

Coelho-Castelo AAM, Panunto-Castelo A, Moreno AN, Dias-Baruffi M, Jamur MC, Oliver C, Roque-Barreira MC, Rodrigues V (2002) Sm60, a mannose-binding protein from Schistosoma mansoni with inflammatory property Int J Parasitol 32: 1747-1754.

Cooke HJ (1984) Influence of enteric cholinergic neurons on mucosal transport in guinea pig ileum. Am J Physiol 246: G263-G267.

Cooke HJ, Wunderlich J, Christofi FL (2003) “The force be with you": ATP in gut mechanosensory transduction. News Physiol Sci 18: 43-49.

Cookson E, Blaxter ML, Selkirk ME (1992) Identification of the major soluble cuticular glycoprotein of lymphatic filarial nematode parasites (gp29) as a secretory form of glutathione peroxidase. Proc Natl Acad Sci USA 89: 5837-5841. 
Cooper ES, Whyte-Alleng CAM, Finzi-Smith JS, McDonald TT (1992) Intestinal nematode infections in children: the pathophysiological price paid. Parasitology 104: S91-S103.

Costa M, Furness JB (1983) The originations, pathways and terminations of neurones with VIP-like immunoreactivity in the guinea pig small intestine. Neuroscience 8: 665-676.

Criado AF, Armas SC, Gimenez CP, Casado NE, Jimenez AG, Rodriguez FC (1992) Proteolytic enzymes from Trichinella spiralis larvae. Vet Parasitol 45: 133-140.

Cross AR, Jones OT (1991) Enzymic mechanisms of superoxide production. Biochim Biophys Acta 1057: 281-298

Cundell DR, Gerard NP, Gerard C, Idanpaan-Heikkila I, Tuomanen EI (1995) Streptococcus pneumoniae anchor to activated human cells by the receptor for platelet-activating factor. Nature 377: 435-438.

Dainichi T, Maekawa Y, Ishii K, Zhang T, Nashed BF, Sakai T, Takashima M, Himeno K (2001) Nippocystatin, a cysteine protease inhibitor from Nippostrongylus brasiliensis, inhibits antigen processing and modulates antigen-specific immune response. Infect Immun 69: 7380-7386.

Dalton JP, Smith AM, Clough KA, Brindley PJ (1995) Digestion of haemoglobin by schistosomes: 35 years on. Parasitol Today 11: 299-303.

Das L, Datta N, Bandyopadhyay S, Das PK (2001) Successful therapy of lethal murine visceral leishmaniasis with cystatin involves up-regulation of nitric oxide and a favorable T-cell response. J Immunol 166: 4020-4028.

Daub J, Loukas A, Pritchard DI, Blaxter M (2000) A survey of genes expressed in adults of the human hookworm Necator americanus. Parasitology 120: 171-184.

Davies SJ, Pearce EJ (1995) Surface-associated serine-threonine kinase in Schistosoma mansoni. Mol Biochem Parasitol 70: 33-44.

Deehan MR, Goodridge HS, Blair D, Lochnit G, Dennis RD, Geyer R, Harnett MM, Harnett W (2002) Immunomodulatory properties of Ascaris suum glycosphingolipids-phosphorylcholine and non-phosphorylcholine-dependent effects. Parasite Immunol 24: 463-469.

Delaney A, Williamson A, Brand A, Ashcom J, Varghese G, Goud GN, Hawdon JM (2005) Cloning and characterisation of an aspartyl protease inhibitor (API-1) from Ancylostoma hookworms. Int J Parasitol 35: 303-313.

Despommier DD, Gold AM, Buck SW, Capo V, Silberstein D (1990) Trichinella spiralis secreted antigen of the infective L1 larva localizes to the cytoplasm and nucleoplasm of infected host cells. Exp Parasitol 71: 27-38.

Devaney E, Jecock RM (1991) The expression of the $M_{r}$ 30,000 antigen in the third stage larvae of Brugia pahangi. Parasite Immunol 13: 75-87.

Di Virgilio F, Borea PA, Illes P (2001) P2 receptors meet the immune system. Trends Pharmacol Sci 22: 5-7.

Dirgahayu P, Fukumoto S, Miura K, Hirai K (2002) Excretory/secretory products from plerocercoids of Spirometra erinaceieuropaei suppress the TNF- $\alpha$ gene expression by reducing phosphorylation of ERK1/2 and p38 MAPK in macrophages. Int J Parasitol 32: 1155-1162.

Dirgahayu P, Fukumoto S, Tademoto S, Kina Y, Hirai K (2004) Excretory/secretory products from plerocercoids of Spirometra erinaceieuropaei suppress interleukin-1 $\beta$ gene expression in murine macrophages. Int J Parasitol 34: 577-564.

Don TA, Jones MK, Smyth D, O'Donoghue P, Hotez P, Loukas A (2004) A pore-forming haemolysin from the hookworm, Ancylostoma caninum. Int J Parasitol 34: 1029-1035.
Donnelly S, O'Neill SM, Sekiya M, Mulcahy G, Dalton JP (2005) Thioredoxin peroxidase secreted by Fasciola hepatica induces the alternative activation of macrophages. Infect Immun 73: 166-173.

Drake LJ, Bianco AE, Bundy DAP, Ashall F (1994) Characterization of peptidases of adult Trichuris muris. Parasitology 109: 623-630.

Dzik JM, Gołos B, Jagielska E, Kapała A, Wałajtys-Rode E (2002a) Early response of guinea-pig lungs to Trichinella spiralis infection. Parasite Immunol 24: 369-379.

Dzik JM, Zieliński Z, Gołos B, Jagielska E, Wranicz M, Wałajtys-Rode E (2002b) Effect of cyclosporin A on immunological response in lungs of guinea pigs infected with Trichinella spiralis. Acta Biochim Polon 49: 233-247.

Dzik JM, Gołos B, Jagielska E, Zieliński Z, Wałajtys-Rode E (2004) A non-classical type of alveolar macrophage response to Trichinella spiralis infection. Parasite Immunol 26: 197-205.

Dzik JM, Zieliński Z, Gołos B, Wałajtys-Rode E (2006) Trichinella spiralis infection affects $\mathrm{p}^{4} 7^{\text {phox }}$ protein expression in guinea pig alveolar macrophages. Exp Parasitol 112: 158-163.

Eckelt VH, Liebau E, Walter RD, Henkle-Dürsen K (1998) Primary sequence and activity analyses of a catalase from Ascaris suum. Mol Biochem Parasitol 95: 203-214.

Ehrlich YH, Kornecki E (1987) Extracellular protein phosphorylation systems in the regulation of cellular responsiveness. Prog Clin Biol Res 249: 193-204.

Estes D, Teale J (1991) Biochemical and functional analysis of extracellular stress proteins Mesocestoides corti. J Immunol 147: 3926-3934.

Esumi N, Budarf M, Ciccarelli L, Sellinger B, Kozak CA, Wistow G (1998) Conserved gene structure and genomic linkage for D-dopachrome tautomerase (DDT) and MIF. Mamm Genome 9: 753-757.

Fetterer RH, Rhoads ML (1997a) Characterization of haemolytic activity from adult Haemonchus contortus. Int J Parasitol 27: 1037-1040.

Fetterer RH, Rhoads ML (1997b) The in vitro uptake and incorporation of hemoglobin by adult Haemonchus-contortus. Vet Parasitol 69: 77-87.

Fishelson Z, Amiri P, Friend DS, Marikovsky M, Petitt M, Newport G, McKerrow JH (1992) Schistosoma mansoni: cell-specific expression and secretion of a serine protease during development of cercariae. Exp Parasitol 75: 87-98.

Foster N, Lee DL (1996) A vasoactive intestinal polypeptide-like protein excreted/secreted by Nippostrongylus brasiliensis and its effect on contraction of uninfected rat intestine. Parasitology 112: 97-104.

Foster N, Dean EJ, Lee DL (1994) The effect of homogenates and excretory/secretory products of Nippostrongylus brasiliensis and of acetylcholinesterase on the amplitude and frequency of contractions of uninfected rat intestine in vitro. Parasitology 108: 453-459.

Fuhrman JA (1995) Filarial chitinases. Parasitol Today 11: 259-261.

Fukumoto S, Hirai K, Tanihata T, Ohmori Y, Stuehr DJ, Hamilton DA (1997) Excretory/secretory products from plerocercoids of Spirometra erinaceieuropaei reduce iNOS and chemokine mRNA levels in peritoneal macrophages stimulated with cytokines and/or LPS. Parasite Immunol 19: 325-332.

Gamble HR, Mansfield LS (1996) Characterization of excretory-secretory products from larval stages of Haemonchus contortus cultured in vitro. Vet Parasitol 62: 291-305.

Gardiner CH (1976) Habit and reproductive behavior of Trichinella spiralis. J Parasitol 62: 865-870. 
Garraud O, Nkenfou C, Bradley JE, Perler FB, Nutman TB (1995) Identification of recombinant filarial proteins capable of inducing polyclonal and antigen-specific $\operatorname{IgE}$ and IgG4 antibodies. J Immunol 155: 1316-1325.

Geldhof P, Claerebout E, Knox DP, Jagneessens J, Vercruysse J (2000) Proteinases released in vitro by the parasitic stages of the bovine abomasal nematode Ostertagia ostertagi. Parasitology 121: 639-647.

Ghendler Y, Arnon R, Fishelson Z (1994) Schistosoma mansoni: isolation and characterization of Smpi56, a novel serine protease inhibitor. Exp Parasitol 78: 121-131.

Ghosh I, Eisinger SW, Raghavan N, Scott AL (1998) Thioredoxin peroxidases from Brugia malayi. Mol Biochem Parasitol 91: 207-220.

Gounaris K (2002) Nucleotidase cascades are catalyzed by secreted proteins of the parasitic nematode T. spiralis. Infect Immun 70: 4917-4924.

Gounaris K, Selkirk ME (2005) Parasite nucleotide-metabolizing enzymes and host purinergic signaling Trends Parasitol 21: 17-21.

Gounaris K, Thomas S, Najarro P, Selkirk ME (2001) Secreted variant of nucleoside diphosphate kinase from the intracellular parasitic nematode Trichinella spiralis. Infect Immun 69: 3658-3662.

Gounaris K, Selkirk ME, Sadeghi SJ (2004) A nucleotidase with unique catalytic properties is secreted by Trichinella spiralis. Mol Biochem Parasitol 136: 257-264.

Grencis RK, Entwistle GM (1997) Production of an IFN$\gamma$ homologue by an intestinal nematode: functionally significant or interesting artefact? Parasitology 115: S101-S115.

Guyer RB, Skantar AM, Deering RA (1985) Acid DNase activity from Dictyostelium discoideum. Biochim Biophys Acta 826: 151-153.

Haffner A, Guilavogui AZ, Tischendorf FW, Brattig NW (1998) Onchocerca volvulus: microfilariae secrete elastinolytic and males nonelastinolytic matrix-degrading serine and metalloproteases. Exp Parasitol 90: 26-33.

Halton DW (1997) Nutritional adaptations to parasitism within platyhelminthes. Int J Parasitol 27: 693-704.

Harcus YM, Parkinson J, Fernandez C, Daub J, Selkirk ME, Blaxter ML, Maizels RM (2004) Signal sequence analysis of expressed sequence tags from the nematode Nippostrongylus brasiliensis and the evolution of secreted proteins in parasites. Genome Biol 5: R39.

Harnett W, Harnett MM (1999) Phosphorylcholine: friend or foe of the immune system? Immuol Today 20: 125129.

Harnett W, Worms MJ, Kapil A, Grainger M, Parkhouse RM (1989) Origin, kinetics of circulation and fate in vivo of the major excretory-secretory product of Acanthocheilonema viteae. Parasitology 99: 229-239.

Harnett W, Houston KM, Tate R, Garate T, Apfel H, Adam R, Haslam SM, Panico M, Paxton T, Dell A, Morris H, Brzeski H (1999) Molecular cloning and demonstration of an aminopeptidase activity in a filarial nematode glycoprotein. Mol Biochem Parasitol 104: 11-23.

Harnett W, Harnett MM, Byron O (2003) Structural/functional aspects of ES-62 - a secreted immunomodulatory phosphorylcholine-containing filarial nematode glycoprotein. Curr Protein Pept Sci 4: 59-71.

Hartmann S, Lucius R (2003) Modulation of host immune responses by nematode cystatins. Int J Parasitol 33: 1291-1302.

Hartmann S, Adam R, Marti T, Kirsten C, Seidinger S, Lucius $\mathrm{R}$ (1997a) A 41-kDa antigen of the rodent filaria Acanthocheilonema viteae with homologies to tropomyosin induces host-protective immune responses. Parasitol Res 83: 390-393.
Hartmann S, Kyewski B, Sonnenburg B, Lucius R (1997b) A filarial cysteine protease inhibitor down-regulates $\mathrm{T}$ cell proliferation and enhances interleukin-10 production. Eur J Immunol 27: 2253-2260.

Hasko G, Cronstein BN (2004) Adenosine an endogenous regulator of innate immunity. Trends Immunol 25: 33-39.

Haslam SM, Houston KM, Harnett W, Reason AJ, Morris HR, Dell A (1999) Structural studies of N-glycans of filarial parasites. Conservation of phosphorylcholinesubstituted glycans among species and discovery of novel chito-oligomers. J Biol Chem 274: 20953-20960.

Hawdon JM, Jones BJ, Perregaux MA, Hotez PJ (1995) Ancylostoma caninum: metalloprotease release coincides with activation of infective larvae in vitro. Exp Parasitol 80: 205-211.

Henkle-Dührsen K, Kampkötter A (2001) Antioxidant enzyme families in parasitic nematodes. Mol Biochem Parasitol 114: 129-141.

Hey AS, Theander TG, Hviid L, Hazrati SM, Kemp M, Kharazami A (1994) The major surface glycoprotein (gp63) from Leishmania major and Leishmania donovani cleaves CD4 molecules on human T cells. J Immunol 152: $4542-4548$.

Hoffmann KF, Wynn TA, Dunne DW (2002) Cytokine-mediated host responses during schistosome infections; walking the fine line between immunological control and immunopathology. Adv Parasitol 52: 265-307.

Hotez PJ, Cerami A (1983) Secretion of an antiproteolytic coagulant by Ancylostoma hookworms. J Exp Med 157: 1594-1603.

Jaffe JJ, Lambert RA (1986) Glutathione S-transferase in adult Dirofilaria immitis and Brugia pahangi. Mol Biochem Parasitol 20: 199-206.

James ER (1994) Superoxide dismutase. Parasitol Today 10: 481-484.

Jasmer DP (1993) Trichinella spiralis infected skeletal muscle cells arrest in G2/M and cease muscle gene expression. J Cell Biol 121: 785-792.

Jasmer DP (1995) Trichinella spiralis: subversion of differentiated mammalian skeletal muscle cells. Parasitol Today 11: $185-188$.

Jolodar A, Miller DJ (1998) Identification of a novel family of non-lysosomal aspartic proteases in nematodes. Biochim Biophys Acta 1382: 13-16.

Jolodar A, Fischer P, Bergmann S, Büttner Hammerschmidt S, Brattig NW (2003) Molecular cloning of an $\alpha$-enolase from the human filarial parasite Onchocerca volvulus that binds human plasminogen. Biochim Biophys Acta 1627: $111-120$.

Jong AY, Chen SH, Stins MF, Kim KS, Tuan TL, Huang SH (2003) Binding of Candida albicans enolase to plasmin(ogen) results in enhanced invasion of human brain microvascular endothelial cells. J Med Microbiol 52: $615-622$.

Kageyama T (1998) Molecular cloning, expression and characterization of an Ascaris inhibitor for pepsin and cathepsin E. Eur J Biochem 253: 804-809.

Kang SW, Baines IC, Rhee SG (1998) Characterization of mammalian peroxiredoxin that contains one conserved cysteine. J Biol Chem 273: 6303-6311.

Karanu FN, Rurangirwa FR, McGuire TC, Jasmer DP (1993) Haemonchus contortus: identification of proteases with diverse characteristics in adult worm excretorysecretory products. Exp Parasitol 77: 362-371.

Kato Y, Muto T, Tomura T, Tsumura H, Watarai H, Mikayama T, Ishizaka K, Kuroki R (1996) The crystal structure of human glycosylation-inhibiting factor is a 
trimeric barrel with three 6-stranded $\beta$-sheets. Proc Natl Acad Sci USA 93: 3007-3010.

Kazura JW, Meshnick SR (1984) Scavenger enzymes and resistance to oxygen-mediated damage in Trichinella spiralis. Mol Biochem Parasitol 10: 1-10.

Kennedy MW, Harnett W, ed (2001) Parasitic Nematodes Molecular Biology Biochemistry and Immunology, CABI Publishing.

Kinet JP (1989) Antibody-cell interactions: Fc receptors. Cell 57: 351-354.

King CL, Medhat A, Malhotra I, Nafeh M, Helmy A, Khaudary J, Ibrahim S, El-Sherbiny M, Zaky S, Stupi RJ, Brustoski K, Shehata M, Shata MT (1996) Cytokine control of parasite-specific anergy in human urinary schistosomiasis. IL-10 modulates lymphocyte reactivity. J Immunol 156: 4715-4721.

Kishimoto Y, Hiraiwa M, O'Brien JS (1992) Saposins: structure, function, distribution, and molecular genetics. J Lipid Res 33: 1255-1267.

Kleemann R, Mischke R, Kapurniotu A, Brunner H, Bernhagen J (1998) Specific reduction of insulin disulfides by macrophage migration inhibitory factor (MIF) with glutathione and dihydrolipoamide: potential role in cellular redox processes. FEBS Lett 430: 191-196.

Knight PA, Wright SH, Lawrence CE, Paterson YYW, Miller HRP (2000) Delayed expulsion of the nematode Trichinella spiralis in mice lacking the mucosal mast cellspecific granule chymase, mouse mast cell protease-1. J Exp Med 192: 1849-1856

Knox DP (1994) Parasite enzymes and the control of roundworm and fluke infestation in domestic animals. Br Vet J 150: 319-337.

Kong Y, Chung YB, Cho SY, Kang SY (1994) Cleavage of immunoglobulin $G$ by excretory-secretory cathepsin Slike protease of Spirometra mansoni plerocercoid. Parasitology 109: 611-621.

Kotze AC, McClure SJ (2001) Haemonchus contortus utilises catalase in defence against exogenous hydrogen peroxide in vitro. Int J Parasitol 31: 1563-1571.

Kwatia MA, Botkin DJ, Williams DL (2000) Molecular and enzymatic characterization of Schistosoma mansoni thioredoxin peroxidase. J Parasitol 86: 908-915.

Lackey A, James ER, Sakanari JA, Resnick SD, Brown M, Bianco AE, McKerrow JH (1989) Extracellular protease of Onchocerca. Exp Parasitol 68: 176-185.

Lähteenmäki K, Kuusela P, Korhonen TK (2001) Bacterial plasminogen activators and receptors. FEMS Microbiol Rev 25: 531-552.

Lee DL (1996) Why do some nematode parasites of the alimentary tract secrete acetylcholinesterase? Int J Parasitol 26: 499-508.

Lee DL, Foster N (1995) Gastrointestinal nematodes and host gut motility. Helminthologia 32: 107-110.

Lee DL, Ko RC, Yi XY, Yeung MH (1991) Trichinella spiralis: antigenic epitopes from the stichocytes detected in the hypertrophic nuclei and cytoplasm of the parasitized muscle fibre (nurse cell) of the host. Parasitology 102: 117-123.

Lee JY, Cho PY, Kim TY, Kang SY, Song KY, Hong SJ (2002) Hemolytic activity and developmental expression of pore-forming peptide, clonorin. Biochem Biophys Res Commun 296: 1238-1244.

Leid RW, Suquet CM, Bouver HG, Hinrichs DJ (1986) Interleukin inhibition by a parasite proteinase inhibitor, taeniaestatin. J Immunol 137: 2700-2702.

Liebau E, Wildenburg G, Walter RD, Henkle-Duhrsen K (1994) A novel type of glutathione S-transferase in Onchocerca volvulus. Infect Immun 62: 4762-4767.
Lim MJ, Chae HZ, Rhee SG, Yu DY, Lee KK, Yeom YI (1998) The type II peroxiredoxin gene family of the mouse: molecular structure, expression and evolution. Gene 216: 197-205.

Linden J (2001) Molecular approach to adenosine receptors: receptor-mediated mechanisms of tissue protection. Annu Rev Pharmacol Toxicol 41: 775-787.

Loukas A, Maizels RA (2000) Helminth C-type lectins and host-parasite interactions. Parasitol Today 16: 333-339.

Loukas A, Mullin NP, Tetteh KK, Moens L, Maizels RM (1999) A novel C-type lectin secreted by a tissue-dwelling parasitic nematode. Curr Biol 9: 825-828.

Loukas A, Doedens A, Hintz M, Maizels RM (2000) Identification of a new C-type lectin, TES-70, secreted by infective larvae of Toxocara canis, which binds to host ligands. Parasitology 121: 545-554.

Lu W, Egerton GL, Bianco AE, Williams SA (1998) Thioredoxin peroxidase from Onchocerca volvulus: a major hydrogen peroxide detoxifying enzyme in filarial parasites. Mol Biochem Parasitol 91: 221-235.

Lun HM, Mak CH, Ko RC (2003) Characterization and cloning of metallo-proteinase in the excretory/secretory products of the infective stage larva of Trichinella spiralis. Parasitol Res 90: 27-37.

Lustigman S, Brotman B, Huima T, Prince AM, McKerrow JH (1992) Molecular cloning and characterization of onchocystatin, a cysteine proteinase inhibitor of Onchocerca volvulus. J Biol Chem 267: 17339-17346.

Machado DC, Horton D, Harrop R, Peachell PT, Helm BA (1996) Potential allergens stimulate the release of mediators of the allergic response from cells of mast cell lineage in the absence of sensitization with antigenspecific IgE. Eur J Immunol 26: 2972-2980.

Maizels RM, Gomez-Escobar N, Gregory WF, Murray J, Zang X (2001) Immune evasion genes from filarial nematodes. Int J Parasitol 31: 889-898.

Mak CH, Ko RC (1999) Characterization of endonuclease activity from excretory/secretory products of a parasite nematode Trichinella spiralis. Eur J Biochem 260: 477-481.

Mak CH, Ko RC (2001) DNA-binding activity in the excretory-secretory products of Trichinella pseudospiralis. Parasitology 123: 301-308.

Mak CH, Chung YYY, Ko RC (2000) Single-stranded endonuclease activity in the excretory-secretory products of Trichinella spiralis and Trichinella pseudospiralis. Parasitology 120: 527-533.

Makita H, Nishimura M, Miyamoto K, Nakano T, Tanino Y, Hirokawa J, Nishihira J, Kawakami Y (1998) Effect of anti-macrophage migration inhibitory factor antibody on lipopolysaccharide-induced pulmonary neutrophil accumulation. Am J Respir Crit Care Med 158: 573-579.

Manoury B, Gregory WF, Maizels RM, Watts C (2001) BmCPI-2, a cystatin homolog secreted by the filarial parasite Brugia malayi, inhibits class II MHC-restricted antigen processing. Curr Biol 11: 447-451.

Marshall CJ (1993) Evolutionary relationships among the serpins. Philos Trans $R$ Soc Lond Biol Sci 342: 101-119.

Martzen MR, Geise GL, Hogan BJ, Peanasky RJ (1985) Ascaris suum: localization by immunochemical and fluorescent probes of host proteases and parasite proteinase inhibitors in cross-sections. Exp Parasitol 60: 139-149.

Martzen MR, McMullen BA, Smith NE, Fujikawa K, Peanasky RJ (1990) Primary structure of the major pepsin inhibitor from the intestinal parasitic nematode Ascaris suum. Biochemistry 29: 7366-7372.

Maruyama H, Nawa Y (1997) Strongyloides venezuelenzis: adhesion of adult worms to culture vessels by orally secreted mucosubstances. Exp Parasitol 85: 10-15. 
McCloskey MA, Fan Y, Luther S (1999) Chemotaxis of rat mast cells toward adenine nucleotides. I Immunol 163: 970-977.

McDermott JR, Bartram RE, Knight PA, Miller HRP, Garrod DR, Grencis RK (2003) Mast cells disrupt epithelial barrier function during enteric nematode infection. Proc Natl Acad Sci USA 100: 7761-7766.

McGonigle S, Curley GP, Dalton JP (1997) Cloning of peroxiredoxin, a novel antioxidant enzyme, from the helminth parasite Fasciola hepatica. Parasitology 115: 101-104.

McGonigle S, Curley GP, Dalton JP (1998) Peroxiredoxins: a new antioxidant family. Parasitol Today 14: 139-145.

McKerrow JH (1989) Parasite proteases. Exp Parasitol 68: 111-115.

McKerrow JH, Sun E, Rosenthal PJ, Bouvier J (1993) The proteases and pathogenicity of parasitic protozoa. Annu Rev Microbiol 47: 821-853.

McLaren DJ, Hockley DJ (1977) Blood flukes have a double outer membrane. Nature 269: 147-149.

Mei H, LoVerde PT (1997) Schistosoma mansoni: the developmental regulation and immunolocalization of antioxidant enzymes. Exp Parasitol 86: 69-78.

Mitchell GF (1989) Glutathione S-transferases - potential components of anti-schistosome vaccines? Parasitol Today 5: 34-37.

Mkoji GM, Smith JM, Prichard RK (1988) Antioxidant systems in Schistosoma mansoni: correlation between susceptibility to oxidant killing and the levels of scavengers of hydrogen peroxide and oxygen free radicals. Int J Parasitol 18: 661-666.

Moczoń T (1994) A cysteine proteinase in the cercariae Diplostomum pseudospathaceum (Trematoda Diplostomatidae). Parasitol Res 80: 680-683.

Moczoń T (1996) A serine proteinase in the penetration glands of the hexacanths Hymenolepis diminuta (Cestoda, Cyclophyllidea). Parasitol Res 82: 67-71.

Moczoń T, Wranicz M (1999) Trichinella spiralis: proteinases in the larvae. Parasitol Res 85: 47-58.

Moerman DG (1999) A metalloprotease prepares the way. Curr Biol 9: R701-R703.

Molinari JL, Mejia H, White AC Jr, Garrido E, BorgonioVM, Baig S, Tato P (2000) Taenia solium: a cysteine protease secreted by metacestodes depletes human CD4 lymphocytes in vitro. Exp Parasitol 94: 133-142.

Moncada DM, Kammanadiminti SJ, Chadee K (2003) Mucin and Toll-like receptors in host defense against intestinal parasites. Trends Parasitol 19: 305-311.

Morales FC, Furtado DR, Rumjanek FD (2004) The N-terminus moiety of the cystatin SmCys from Schistosoma mansoni regulates its inhibitory activity in vitro and in vivo. Mol Biochem Parasitol 134: 65-73.

Mosser DM (2003) The many faces of macrophage activation. J Leukoc Biol 73: 209-212.

Mueller JF (1963) Parasite induced weight gain in mice. Ann N Y Acad Sci 113: 217-233.

Mueller JF (1974) The biology of Spirometra. J Parasitol 60: 3-14.

Nakagawa TY, Rudensky AY (1999) The role of lysosomal proteinases in MHC class II-mediated antigen processing and presentation. Immunol Rev 172: 121-129.

Newlands GF, Skuce PJ, Knox DP, Smith WD (2001) Cloning and expression of cystatin, a potent cysteine protease inhibitor from the gut of Haemonchus contortus. Parasitology 122: 371-378.

Nicklin MJ, Barrett AJ (1984) Inhibition of cysteine proteinases and dipeptidyl peptidase I by egg-white cystatin. Biochem J 223: 245-253.
Nor ZM, Houston KM, Devaney E, Harnett W (1997) Variation in the nature of attachment of phosphorylcholine to excretory-secretory products of adult Brugia pahangi. Parasitology 114: 257-262.

O'Connor RA, Jenson JS, Devaney E (2000) NO contributes to proliferative suppression in a murine model of filariasis. Infect Immun 68: 6101-6107.

Okabe T, Mori H, Ohyama T (1997) Deoxyribonuclease secreted from an insectivorous plant Drosera adelae. $\mathrm{Nu}$ cleic Acids Symp Ser 37: 127-128.

O'Neill SM, Mills KHG, Dalton JP (2001) F. hepatica cathepsin L cysteine proteinase suppresses Bordetella pertusis-specific IFN- $\gamma$ production in vivo. Parasite Immunol 23: 541-547.

Osaki Y (1990) Ultrastructural studies on the plerocercoid of Spirometra erinacei in experimental sparganosis. Parasitol Res 76: 466-472.

Osborne J, Devaney E (1999) Interleukin-10 and antigenpresenting cells actively suppress Th1 cells in BALB/c mice infected with the filarial parasite Brugia pahangi. Infect Immun 67: 1599-1605.

Ou X, Thomas GR, Chacon MR, Tang L, Selkirk ME (1995) Brugia malayi: differential susceptibility to and metabolism of hydrogen peroxide in adults and microfilariae. Exp Parasitol 80: 530-540.

Page AP, Hamilton AJ, Maizels RM (1992) Toxocara canis: monoclonal antibodies to carbohydrate epitopes of secreted (TES) antigens localize to different secretionrelated structures in infective larvae. Exp Parasitol 75: 56-71.

Palanivel V, Posey C, Horauf AM, Solbach W, Piessens WF, Harn DA (1996) B-cell outgrowth and ligand-specific production of IL-10 correlate with Th2 dominance in certain parasitic diseases. Exp Parasitol 84: 168-177.

Pancholi V (2001) Multifunctional $\alpha$-enolase: its role in diseases. Cell Mol Life Sci 58: 902-920.

Panesar TS (1981) The early phase of tissue invasion by Trichuris muris (nematoda: Trichuroidea). Z Parasitenkd 66: $163-166$.

Pastrana DV, Raghavan N, FitzGerald P, Eisinger SW, Metz C, Bucala R, Schleimer RP, Bickel C, Scott AL (1998) Filarial nematode parasites secrete a homologue of the human cytokine macrophage migration inhibitory factor. Infect Immun 66: 5955-5963.

Pennock JL, Behnke JM, Bickle QD, Devaney E, Grencis RK, Isaac RE, Joshua GW, Selkirk ME, Zhang Y, Meyer DJ (1998) Rapid purification and characterization of L-dopachrome-methyl ester tautomerase (macrophagemigration-inhibitory factor) from Trichinella spiralis, Trichuris muris and Brugia pahangi. Biochem J 335: 495-498.

Petitfrere E, Sartelet H, Aguie-Aguie G, Martiny L, Haye B (1996) Evidence for a TSH-controlled ectophosphotyrosine phosphatase in pig thyroid cultured cells. Biochem Biophys Res Commun 220: 746-753.

Phares K (1996) An unusual host-parasite relationship: The growth hormone like factor from plerocercoids of spirometrid tapeworms. Int J Parasitol 26: 575-588.

Phares K, Kubik J (1996) The growth factor from plerocercoids of Spirometra mansonoides is both a growth hormone agonist and a cysteine proteinase. J Parasitol 82: 210-215.

Piedrafita D, Spithill TW, Dalton JP, Brindley PJ, Sandeman MR, Wood PR, Parsons JC (2000) Juvenile Fasciola hepatica are resistant to killing in vitro by free radicals compared with larvae of Schistosoma mansoni. Parasite Immunol 22: 287-295.

Plow EF, Herren T, Redlitz A, Miles LA, Hoover-Plow JL (1995) The cell biology of the plasminogen system. FASEB J 9: 939-945. 
Polzer M, Conradt U (1994a) Identification and partial characterization of the proteases from different developmental stages of Schistocephalus solidus (Cestoda: Pseudophyllidea) Int J Parasitol 24: 967-973.

Polzer M, Overstreet RM, Taraschewski H (1994b) Proteinase activity in the plerocercoid of Proteocephalus ambloplitis (Cestoda). Parasitology 109: 209-213.

Potempa J, Korzus E, Travis J (1994) The serpin family of proteinase inhibitors: structure, function and regulation. J Biol Chem 269: 15957-15600.

Pritchard DI, Brow A, Toutant J-P (1994) The molecular forms of acetylcholinesterase from Necator americanus (Nematoda), a hookworm parasite of the human intestine. Eur J Biochem 219: 317-323.

Prowse RK, Chaplin P, Clem Robinson H, Spithill TW (2002) Fasciola hepatica cathepsin L suppresses lymphocyte proliferation in vitro and modulates surface CD4 expression of human and ovine T cells. Parasite Immunol 24: 57-66.

Rao UR, Salinas G, Mehta K, Klei TR (2000) Identification and localization of glutathione S-transferase as a potential target enzyme in Brugia species. Parasitol Res 86: 908-915.

Redegeld FA, Caldwell CC, Sitkovsky MV (1999) Ecto-protein kinases: ecto-domain phosphorylation as a novel target for pharmacological manipulation? Trends Pharmacol Sci 20: 453-459.

Redlitz A, Fowler BJ, Plow EF, Miles LA (1995) The role of an enolase-related molecule in plasminogen binding to cells. Eur J Biochem 227: 407-415.

Reed MB, Strugnell RA, Panaccio M, Spithill TW (2000) A novel member of the NK-lysin protein family is developmentally regulated and secreted by Fasciola hepatica. Mol Biochem Parasitol 105: 297-303.

Rhoads ML (1983) Trichinella spiralis: identification and purification of superoxide dismutase. Exp Parasitol 56: 41-54.

Rhoads ML (1984) Secretory cholinesterases of nematodes: possible functions in the host-parasite relationship. Trop Veterinarian 2: 3-10.

Rhoads ML, Fetterer RH (1995) Developmentally regulated secretion of cathepsin L-like cysteine proteases by Haemonchus contortus. J Parasitol 81: 505-512.

Rhoads ML, Fetterer RH (1996) Extracellular matrix degradation by Haemonchus contortus. J Parasitol 82: 379-383.

Rhoads ML, Fetterer RH, Hill DE, Urban JF Jr (2000) Trichuris suis: A secretory chymotrypsin/elastase inhibitor with potential as an immunomodulator. Exp Parasitol 95: $36-44$.

Riese RJ, Chapman HA (2000) Cathepsins and compartmentalization in antigen presentation. Curr Opin Immunol 12: 107-113.

Rojas J, Rodriguez-Osorio M, Gomez-Garcia V (1997) Immunological characteristics and localization of the Trichinella spiralis glutathione S-transferase. J Parasitol 83: 630-635.

Rzepczyk CM, Bishop CJ (1984) Immunological and structural aspects of the cell mediated killing of Dirofilaria immitis microfilariae. Parasite Immunol 6: 443-457.

Sajid M, McKerrow JH (2002) Cysteine proteases of parasitic organisms. Mol Biochem Parasitol 120: 1-21.

Satoh Y, Ishikawa K, Oomori Y, Takeda S, Ono K (1992) Bethanechol and a G-protein activator, $\mathrm{NaF} / \mathrm{AlCl}_{3}$, induce secretory response in Paneth cells of mouse intestine. Cell Tissue Res 269: 213-220.

Sayed AA, Williams DL (2004) Biochemical characterization of 2-Cys peroxiredoxins from Schistosoma mansoni. J Biol Chem 279: 26159-26166.
Schierack P, Lucius R, Sonnenburg B, Schilling K, Hartmann S (2003) Parasite-specific immunomodulatory functions of filarial cystatin. Infect Immun 71: 2422-2429.

Schonemeyer A, Lucius R, Sonnenburg B, Brattig N, Sabat R, Schilling K, Bradley J, Hartmann S (2001) Modulation of human $\mathrm{T}$ cell responses and macrophage functions by onchocystatin, a secreted protein of the filarial nematode Onchocerca volvulus. I Immunol 167: 3207-3215.

Schuette CG, Pierstorff B, Huettler S, Sandhoff K (2001) Sphingolipid activator proteins: proteins with complex function in lipid degradation and skin biogenesis. Glycobiology 11: 81R-90R.

Selkirk ME, Hussein AS, Chambers AE, Goulding D, Gares MP, Vasquez-Lopez C, Garate T, Parkhouse RM, Gounaris K (2004) Trichinella spiralis secretes a homologue of prosaposin. Mol Biochem Parasitol 135: 49-56.

Seo MS, Kang SW, Kim K, Baines IC, Lee TH, Rhee SG (2000) Identification of a new type of mammalian peroxiredoxin that forms an intramolecular disulfide as a reaction intermediate. J Biol Chem 275: 20346-20352.

Sharp SE, Phares CK, Heidrick ML (1982) Immunological aspects associated with suppression of hormone levels in rats infected with plerocercoids of Spirometra mansonoides (Cestoda). J Parasitol 686: 993-998.

Shaw RJ, McNeill MM, Maass DR, Hein WR, Barber TK, Wheeler M, Morris CA, Shoemaker CB (2003) Identification and characterisation of an aspartyl protease inhibitor homologue as a major allergen of Trichostrongylus colubriformis. Int J Parasitol 33: 1233-1243.

Shenai BR, Sijvali PS, Singh A, Rosenthal PJ (2000) Characterization of native and recombinant falcipain-2, a principal trophozoite cysteine protease and essential hemoglobinase of Plasmodium falciparum. J Biol Chem 275: 29000-29010.

Shi GP, Bryant RA, Riese R, Verhelst S, Driessen C, Li Z, Bromme D, Ploegh HL, Chapman HA (2000) Role for cathepsin $\mathrm{F}$ in invariant chain processing and major histocompatibility complex class II peptide loading by macrophages. J Exp Med 191: 1177-1186.

Simpson AJ, Singer D, McCutchan TF, Sacks DL, Sher A (1983) Evidence that schistosome MHC antigens are not synthesized by the parasite but are acquired from the host as intact glycoproteins. J Immunol 131: 962-965.

Skelly PJ, Shoemaker CB (1996) Rapid appearance and asymmetric distribution of glucose transporter SGTP4 at the apical surface of intramammalian-stage Schistosoma mansoni. Proc Natl Acad Sci USA 93: 3642-3646.

Smith NC, Bryant C (1989) The effect of antioxidants on the rejection of Nippostrongylus brasiliensis. Parasite Immunol 11: 161-167.

Smith VP, Selkirk ME, Gounaris K (2000) A reversible protein phosphorylation system is present at the surface of the infective larvae of the parasitic nematode Trichinella spiralis. FEBS Lett 483: 104-108.

Soeda S, Hiraiwa M, O’Brien JS, Kishimoto Y (1993) Binding of cerebrosides and sulfatides to saposins A-D. J Biol Chem 268: 18519-18523.

Song CY, Chappel CL (1993) Purification and partial characterization of cysteine proteinase from Spirometra mansoni plerocercoids. J Parasitol 79: 517-524.

Specian RD, Neutra MR (1980) Mechanism of rapid mucus secretion in goblet cells stimulated by acetylcholine. $J$ Cell Biol 85: 629-640.

Spolski RJ, Thomas PG, See EJ, Mooney KA, Kuhn RE (2002) Larval Taenia crassiceps secretes a protein with characteristics of murine IFN- $\gamma$. Parasitol Res 88: 431-438. 
Stassens P, Bergum PW, Gansemans Y, Jespers L, Laroche Y, Huang S, Maki S, Messens J, Lauwereys M, Cappello M, Hotez PJ, Lasters I, Vlasuk GP (1996) Anticoagulant repertoire of the hookworm Ancylostoma caninum. Proc Natl Acad Sci USA 93: 2149-2154.

Stepek G, Houston KM, Goodridge HS, Devaney E, Harnett W (2004) Stage-specific and species-specific differences in the production of the mRNA and protein for the filarial nematode secreted product, ES-62. Parasitology 128: 91-98.

Stewart GL (1983) Pathophysiology of the muscle phase. In Trichinella and Trichinosis (Campbell WC, ed) pp 241-264, Plenum Publishing Corporation, New York

Stöcker W, Zwilling R (1995) Astacin. Methods Enzymol 248: 305-325.

Stöcker W, Grams F, Baumann U, Reinemer P, GomisRuth FX, McKay DB, Bode W (1995) The metzincinstopological and sequential relations between the tacins, adamalysins, serralysins, and matrixins (collagenases) define a superfamily of zinc-peptidases. Protein Sci 4: 823-840.

Street NE, Mosmann TR (1991) Functional diversity of T lymphocytes due to secretion of different cytokine patterns. FASEB J 5: 171-177.

Sugimoto H, Taniguchi M, Nakagawa A, Tanaka I, Suzuki M, Nishihira J (1999) Crystal structure of human Ddopachrome tautomerase, a homologue of macrophage migration inhibitory factor, at $1.54 \AA$ resolution. Biochemistry 38: 3268-3279.

Swan DG, Phillips K, Tait A, Shiels BR (1999) Evidence for localisation of a Theileria parasite AT hook DNA-binding protein to the nucleus of immortalised bovine host cells. Mol Biochem Parasitol 101: 117-129.

Takahasi Y, Homan W, Lim PL (1993) Ultrastructural localization of the phosphorylcholine-associated antigen in Trichinella spiralis. J Parasitol 79: 604-609.

Takeya H, Nishida S, Miyata T, Kawada S, Saisaka Y, Morita T, Iwanaga S (1992) Coagulation factor X activating enzyme from Russell's viper venom (RVV-X). A novel metalloproteinase with disintegrin (platelet aggregation inhibitor)-like and C-type lectin-like domains. J Biol Chem 267: 4109-4117.

Tamashiro WK, Rao M, Scott AL (1987) Proteolytic cleavage of IgG and other protein substrates by Dirofilaria immitis microfilarial enzymes. J Parasitol 73: 149-154.

Tan TH, Edgerton SA, Kumari R, McAlister MS, Roe SM, Nagl S, Pearl LH, Selkirk ME, Bianco AE, Totty NF, Engwerda C, Gray CA, Meyer DJ (2001) Macrophage migration inhibitory factor of the parasitic nematode Trichinella spiralis. Biochem J 357: 373-383.

Tanihata T (1996) Effects of excretory and secretory products from plerocercoids of Spirometra erinaceieuropaei on tumor necrosis factor- $\alpha$ and interleukin- 6 mRNA levels in murine peritoneal macrophages. J Yonago Med Assoc 47: $140-147$.

Tarleton RL, Kemp WM (1981) Demonstration IgG-Fc and C3 receptors on adult Schistosoma mansoni. J Immunol 125: 379-384.

Taylor JB, Vidal A, Torpier G, Meyer DJ, Roitsch C, Balloul JM, Southan C, Sondermeyer P, Pemble S, Lecocq JP, Capron A, Ketterer B (1988) The glutathione transferase activity and tissue distribution of a cloned Mr28K protective antigen of Schistosoma mansoni. EMBO J 7: 465472.

Todorova VK, Stoyanow DI (2000) Partial characterization of serine proteinases secreted by adult Trichinella spiralis. Parasitol Res 86: 684-687.
Todorova VK, Knox DP, Kennedy MV (1995) Proteinase in the excretory/secretory products (ES) of adult Trichinella spiralis. Parasitology 111: 201-208.

Tort J, Brindley PJ, Knox D, Wolfe KH, Dalton JP (1999) Proteinase and associated genes of parasitic helminths. Adv Parasitol 43: 161-266.

Tsuboi T, Oka K, Hirai K, Torii M (1992) Effects of proteinase inhibitors on liver cell growth stimulating activity and cytosolic calcium concentration by the infection of plerocercoids of Spirometra erinacei. Jpn J Parasitol 41: (Suppl) 64.

Tsuji N, Kasuga-Aoki H (2001) Cloning and characterisation of a peroxiredoxin from the swine roundworm Ascaris suum. Int J Parasitol 30: 125-128.

Tume CB, Ngu JL, McKerrow JL, Seigel J, Sun E, Barr PJ, Bathurst I, Morgan G, Nkenfou C, Asonganyi T, Lando G (1997) Characterization of a recombinant Onchocerca volvulus antigen (Ov33) produced in yeast. Am J Trop Med Hyg 57: 626-633.

Verdot L, Lalmanach G, Vercruysse V, Hartmann S, Lucius R, Hoebeke J, Gauthier F, Vray B (1996) Cystatins up-regulate nitric oxide release from IFN- $\gamma$-activated mouse peritoneal macrophages. J Biol Chem 271: 28077-28081.

Vray B, Hartmann S, Hoebeke J (2002) Immunomodulatory properties of cystatins. Cell Mol Life Sci 59: 1503-1512.

Wada K, Sato H, Kinoh H, Kajita M, Yamamoto H, Seiki M (1998) Cloning of three Caenorhabditis elegans genes potentially encoding novel matrix metalloproteinases. Gene 211: 57-62.

Walter J, Schnolzer M, Pyerin W, Kinzel V, Kubler D (1996) Induced release of cell surface protein kinase yields CK1- and CK2-like enzymes in tandem. J Biol Chem 271: 111-119.

Wang H-R, Tanihata T, Fukumoto S, Hirai K, Phares CK (1995) Immunohistochemical localization of a $27 \mathrm{kDa}$ protein in the plerocercoids of Spirometra erinacei. Jpn J Parasitol 44: 6-11.

Weintraub H (1993) The MyoD family and myogenesis: redundancy, networks and thresholds. Cell 75: 1241-1244.

Weis WI, Taylor ME, Drickamer K (1998) The C-type lectin superfamily in the immune system. Immunol Rev 163: 19-34.

Wharton D (1983) The production and functional morphology of helminth egg-shells. Parasitology 786: 85-97.

White AC Jr, Molinari JL, Pillai AV, Rege AA (1992) Detection and preliminary characterization of Taenia solium metacestode proteases. J Parasitol 78: 281-287.

Wijffels GL, Sexton JL, Salvatore L, Pettitt JM, Humphris DC, Panaccio M, Spithill TW (1992) Primary sequence heterogeneity and tissue expression of glutathione Stransferases of Fasciola hepatica. Exp Parasitol 74: 87-99.

Wilson RA, Barnes PE (1979) Synthesis of macromolecules by the epithelial surfaces of Schistosoma mansoni: an autoradiographic study. Parasitology 78: 295-310.

Wright KA (1979) Trichinella spiralis: an intracellular parasite in the intestinal phase. J Parasitol 65: 441-445.

Wu Y, Adam R, Williams SA, Bianco AE (1996) Chitinase genes expressed by infective larvae of the filarial nematodes, Acanthocheilonema viteae and Onchocerca volvulus. Mol Biochem Parasitol 75: 207-219.

Yan L, Leontovich A, Fei K, Sarras MP Jr (2000) Hydra metalloproteinase 1: a secreted astacin metalloproteinase whose apical axis expression is differentially regulated during head regeneration. Dev Biol 219: 115-128.

Yasumasu S, Yamada K, Akasaka K, Mitsunaga K, Iuchi I, Shimada H, Yamagami K (1992) Isolation of cDNAs for LCE and HCE, two constituent proteases of the hatch- 
ing enzyme of Oryzlas latipes, and concurrent expression of their mRNAs during development. Dev Biol 153: 250-258.

Yatsuda AP, Krijgsveld J, Cornelissen AW, Heck AJ, de Vries E (2003) Comprehensive analysis of the secreted proteins of the parasite Haemonchus contortus reveals extensive sequence variation and differential immune recognition. J Biol Chem 278: 16941-16951.

Zaborina O, Li X, Cheng G, Kapatral V, Chakrabarty AM (1999) Secretion of ATP-utilizing enzymes, nucleoside diphosphate kinase and ATPase, by Mycobacterium bovis BCG: sequestration of ATP from macrophage P2Z receptors? Mol Microbiol 31: 1333-1343.
Zang X, Maizels RM (2001) Serine proteinase inhibitors from nematodes and the arms race between host and pathogen Trends Biochem Sci 26: 191-197.

Zang X, Yazdanbakhsh M, Jiang H, Kanost MR, Maizels RM (1999) A novel serpin expressed by the bloodborne microfilariae of the parasitic nematode Brugia malayi inhibits human neutrophil serine proteinases. Blood 94: 1418-1428.

Zelck UE, Von Janowsky B (2004) Antioxidant enzymes in intramolluscan Schistosoma mansoni and ROS-induced changes in expression. Parasitology 128: 493-501. 